\title{
Insights into the metabolism and microbial biotransformation of dietary flavan-3-ols and the bioactivity of their metabolites
}

\author{
Maria Monagas, ${ }^{* a}$ Mireia Urpi-Sarda, ${ }^{b}$ Fernando Sánchez-Patán, ${ }^{a}$ Rafael Llorach, ${ }^{b}$ Ignacio Garrido, ${ }^{a}$ \\ Carmen Gómez-Cordovés, ${ }^{a}$ Cristina Andres-Lacueva ${ }^{b}$ and Begoña Bartolomé ${ }^{a}$
}

\author{
Received 5th September 2010, Accepted 25th October 2010 \\ DOI: 10.1039/c0fo00132e
}

\begin{abstract}
Flavan-3-ols, occurring in monomeric, as well as in oligomeric and polymeric forms (also known as condensed tannins or proanthocyanidins), are among the most abundant and bioactive dietary polyphenols, but their in vivo health effects in humans may be limited because of their recognition as xenobiotics. Bioavailability of flavan-3-ols is largely influenced by their degree of polymerization; while monomers are readily absorbed in the small intestine, oligomers and polymers need to be biotransformed by the colonic microbiota before absorption. Therefore, phenolic metabolites, rather than the original high molecular weight compounds found in foods, may be responsible for the health effects derived from flavan-3-ol consumption. Flavan-3-ol phenolic metabolites differ in structure, amount and excretion site. Phase II or tissular metabolites derived from the small intestine and hepatic metabolism are presented as conjugated derivatives (glucuronic acid or sulfate esters, methyl ether, or their combined forms) of monomeric flavan-3-ols and are preferentially eliminated in the bile, whereas microbial metabolites are rather simple conjugated lactones and phenolic acids that are largely excreted in urine. Although the colon is seen as an important organ for the metabolism of flavan-3-ols, the microbial catabolic pathways of these compounds are still under consideration, partly due to the lack of identification of bacteria with such capacity. Studies performed with synthesized or isolated phase II conjugated metabolites have revealed that they could have an effect beyond their antioxidant properties, by interacting with signalling pathways implicated in important processes involved in the development of diseases, among other bioactivities. However, the biological properties of microbederived metabolites in their actual conjugated forms remain largely unknown. Currently, there is an increasing interest in their effects on intestinal infections, inflammatory intestinal diseases and overall gut health. The present review will give an insight into the metabolism and microbial biotransformation of flavan-3-ols, including tentative catabolic pathways and aspects related to the identification of bacteria with the ability to catabolize these kinds of polyphenols. Also, the in vitro bioactivities of phase II and microbial phenolic metabolites will be covered in detail.
\end{abstract}

\section{Introduction}

Proanthocyanidins or condensed tannins are polymers of flavan3-ols and are among the most abundant polyphenols in our diet. Proanthocyanidins exhibit a wide range of biological activities, including antioxidant, anti-carcinogenic, cardioprotective, antimicrobial and neuro-protective activities, as has been demonstrated in many in vitro and ex vivo studies. ${ }^{1}$ In the last decade, a large body of epidemiological data has been accumulated supporting the assumption that the consumption of flavan-3-olrich food such as cocoa, red wine or tea may reduce the risk of coronary heart disease (CHD). ${ }^{2-4}$ Proanthocyanidins exhibit a high structural diversity and a wide range of degree of polymerization (DP), and their content varies considerably between the different plant sources. Procyanidins, consisting of (epi)catechin units, are the most abundant type of proanthocyanidins in nature. Propelargonidins and prodelphinidins

${ }^{a}$ Institute of Industrial Fermentations (CSIC), Juan de la Cierva 3, 28006 Madrid, Spain.E-mail: monagas@ifi.csic.es

${ }^{b}$ Department of Nutrition and Food Science, Xarta, INSA, Pharmacy School, University of Barcelona, Av/Joan XXIII s/n., 08028 Barcelona, Spain contain (epi)afzelechin and (epi)gallocatechin units, respectively, and are usually mixed with procyanidins. With regard to the interflavanic bond nature, B-type procyanidins [C-4 (upper unit) $\rightarrow$ C-6 or C-8 (lower unit)] are more abundant than A-type procyanidins, which contain an additional ethertype bond [C-2 (upper unit)-O-C-7 (lower unit)]. Fruits (grapes, apples and pears), legumes, cocoa and beverages such as wine, cider and beer are among the most important sources of B-type proanthocyanidins. ${ }^{5}$ Polymeric proanthocyanidins with DP $>10$ represent the largest amount in 21 kinds of food. ${ }^{5}$ The daily intake of flavan-3-ols in the United States has been estimated to be around $60 \mathrm{mg} /$ day for proanthocyanidins with a DP $<2 .{ }^{5} \mathrm{In}$ the Spanish population it has been estimated to be $18-31 \mathrm{mg} /$ day when considering proanthocyanidins with a DP up to $3,{ }^{6}$ and $450 \mathrm{mg} /$ day when considering highly polymerized proanthocyanidins. $^{7}$

Polyphenols are recognized as xenobiotics (i.e. foreign or artificial substances, usually of synthetic origin) by the human organism, and therefore bioavailability is a factor that limits the health benefits derived from proanthocyanidin consumption. Bioavailability of proanthocyanidins is largely influenced by their DP. While monomeric flavan-3-ols are readily absorbed in 
the small intestine, oligomeric and polymeric forms pass intact through the gastrointestinal tract, reaching the colon where they are transformed by the intestinal microbiota before absorption. The scientific evidence accumulated during the last decade indicates that the beneficial effect of these phytochemicals could be attributed to the conjugated metabolites (formed during the phase II metabolism of monomeric flavan-3-ols), and mainly to metabolites derived from the microbial catabolism of proanthocyanidins, rather than to the original forms found in food which have been widely used in most bioactivity studies. ${ }^{8-10}$ Recent studies have estimated that the amount of non-absorbable polyphenols reaching the colon is very high and that microbe-derived phenolic metabolites excreted in urine represent the largest proportion of polyphenol intake. This recognition is leading to a reformulation of estimated bioavailability values and the potential bioactivity of polyphenols. ${ }^{11}$ Currently, there is an increasing interest in the determination of the possible health implications derived from the interaction between phenolic compounds and human microbiota, in particular concerning the effect on microbiota composition and gut health. However, the biological properties of microbial-derived metabolites are still largely unknown.

The aim of the present review is to provide updated information on metabolites formed from dietary flavan-3-ols, as well as their bioactivity and potential health effects. After giving a general overview about the bioavailability of dietary flavan-3ols in humans, structures of main phase II or tissular metabolites derived from small intestine and liver metabolism are presented.
A special section is dedicated to the microbial catabolism of monomeric flavan-3-ols and proanthocyanidins, describing possible catabolic pathways, microbial reactions, and characteristic metabolites derived from the biotransformation process. Intrisic characteristics of candidate catabolic bacteria and structural flavan-3-ol features limiting bacteria degradation are also discussed. Finally, the main biological activities reported for both phase II or tissular and microbial metabolites derived from flavan-3-ols are reviewed, taking into consideration the results of studies performed with conjugated metabolites at in vivo concentrations.

\section{Bioavailability of monomeric flavan-3-ols and proanthocyanidins}

Bioavailability is a key issue linking polyphenols and health effects. In the case of flavan-3-ols, the degree of polymerization (DP) and galloylation are factors affecting their bioavailability (Fig. 1). Monomeric flavan-3-ols are absorbed in the small intestine and extensively metabolized into glucuronide conjugates by phase II enzymes. ${ }^{12,13}$ These metabolites can reach the systemic circulation or be eliminated in the bile. Further metabolism into sulfate conjugates and methyl derivatives occurs in the liver. However, oligomers with DP $>3$ and polymers are not absorbed in the small intestine and reach the colon, where they are subjected to microbial catabolism. Microbial metabolites are further absorbed and metabolized by phase II enzymes, to finally enter the circulation or be eliminated in urine.

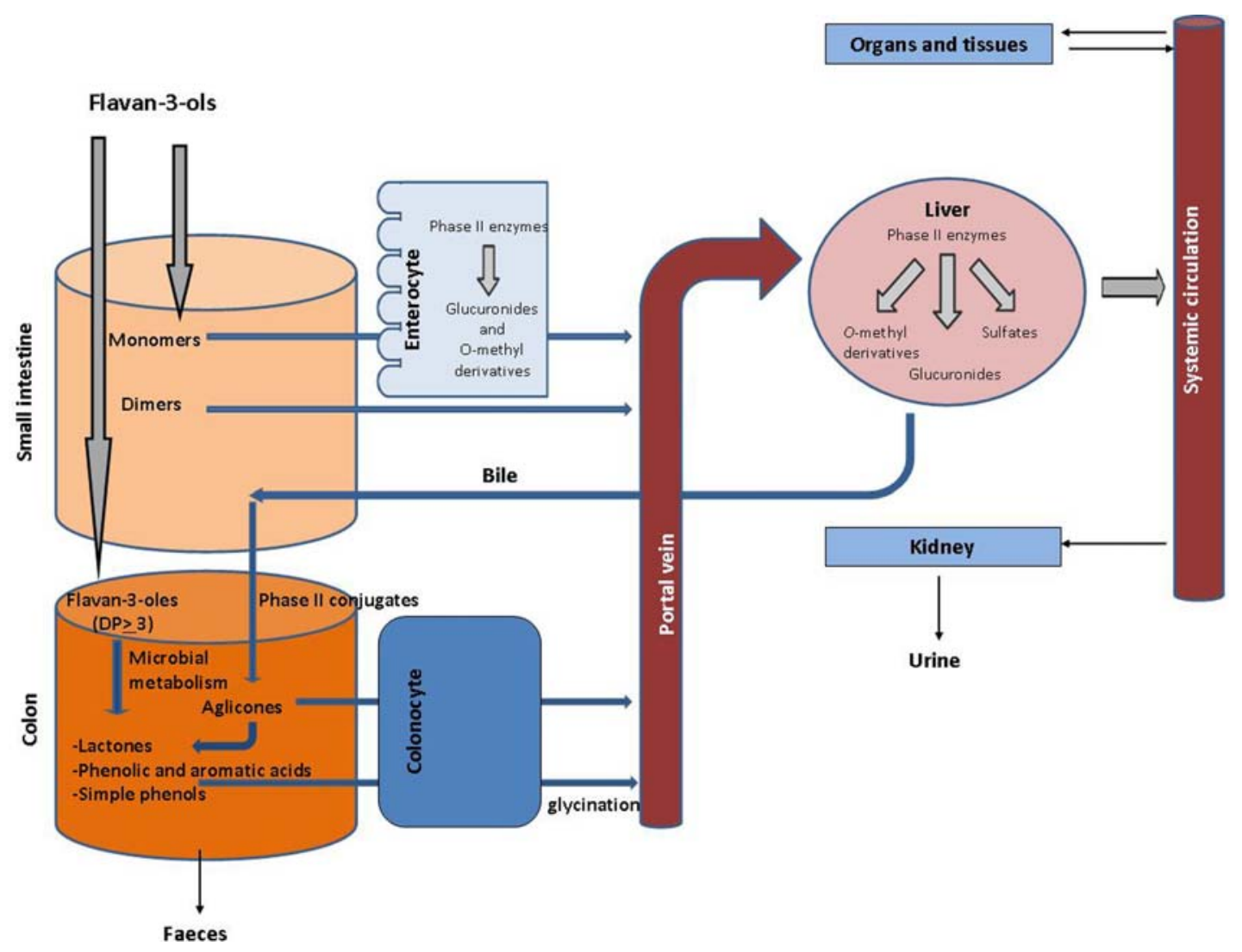

Fig. 1 Schematic diagram of organs, reactions and agents involved in the bioavailability of flavan-3-ols. 


\section{II.1 Absorption and metabolism of monomeric flavan-3-ols}

With regard to small intestine and liver metabolism, the small intestine is the main site for glucuronidation, which occurs in the luminal part of the endoplasmic reticulum via the superfamily of uridine 5'-diphosphate glucuronosyltransferases (UGTs). In particular, UGT1 is considered to be responsible for the glucuronidation of flavonoids. ${ }^{14}$ Sulfation and methylation mainly occur in the liver through cytosol sulfotransferases (SULT) and catechol- $O$-methyltransferase (COMT). Specifically, SULTA1 and SULTA3 are considered to be responsible for the sulfation of (-)-epicatechin. ${ }^{15}$ The preferred positions for conjugation are the hydroxyl groups at $\mathrm{C}-3^{\prime}$ and $\mathrm{C}-4^{\prime}$ (B ring), and C-5 and C-7 (A ring) (Fig. 2). Generally, conjugated metabolites of (-)-epicatechin are presented in the form of monoglucuronides (5-, 7- and -3'-O-glucuronides), sulfates (7-O-sulfate), methyl ethers ( $3^{\prime}$ - and $4^{\prime}-O$-methyl) or as combined derivatives $\left(3^{\prime}-O\right.$-methyl-7- $O$-glucuronide, $4^{\prime}-O$-methyl 5- or -7$O$-glucuronide). ${ }^{16-19}$ In the case of (-)-epigallocatechin (EGC), the $3^{\prime}-$ and 7-O-glucuronides and the $4^{\prime}-O$-methyl and its derivatives (4'-O-methyl-3'-O-glucuronide, $4^{\prime}$ - $O$-methyl-7- $O$ glucuronide, and $4^{\prime}$-O-methyl- $3^{\prime}$-sulfate) have been identified following consumption of green tea. ${ }^{20-24}$

In general, $O$-sulfated metabolites of (-)-epicatechin are the predominant metabolites in urine samples after the intake of a single nutritional dose of cocoa powder in humans. ${ }^{25}$ However, $O$-methyl- $O$-sulfate derivatives of $(-)$-epicatechin have been found as major urinary metabolites, followed by glucuronide, sulfate and methyl-glucuronide conjugates, after the intake by humans of a single dose of flavonol-rich cocoa powder. ${ }^{26}$ Major urinary amounts of (epi)catechin- $O$-methyl- $O$-sulfates, followed by sulfates and glucuronide conjugates, have also been reported after the intake of a single dose of tea extracts in humans. ${ }^{27-29}$ Among $O$-glucuronides, the $3^{\prime}-O$-glucuronide is the main glucuronide derivative of both (-)-epicatechin and EGC in humans. ${ }^{17,22,24,30}$ EGC-4'-O-methyl is the major methylated metabolite of EGC after tea intake in humans. ${ }^{23}$

Among the different pairs of diastereomers, (-)-epicatechin presents higher absorption than (+)-catechin, ${ }^{16}$ but the latter is more bioavailable than $(-)$-catechin. ${ }^{31}$ With regard to galloylated monomers, (-)-epicatechin-3-O-gallate (ECG) seems to be better absorbed than (-)-epigallocatechin-3-O-gallate (EGCG), ${ }^{27-29,32}$ but is considerably less bioavailable than the non-galloylated monomers. No conjugated metabolites of the 3-O-galloylated flavan-3-ols (ECG and EGCG) have been detected in biological fluids. The possible hydrolysis of ECG after absorption was suggested at first, but no esterases have been described in plasma or liver, being found only at the level of the oral cavity. ${ }^{33}$ It has been suggested that the low $C_{\max }$ of EGCG is probably due to not all possible conjugated forms being identified, particularly those conjugated in the gallic acid ring such as EGCG-4" $-O$ methyl, EGCG-4',4"-di- $O$-methyl, and EGCG-4" $-O$-glucuronide $^{24,34}$ (Fig. 2). Recently, a new 7-O-glucopyranosyl-EGCG$4^{\prime \prime}$ - $O$-glucopyranoside has also been identified. ${ }^{21}$ Other studies have confirmed that both ECG and EGCG, but in particular the latter, also appear in unmetabolized form in plasma. ${ }^{28,35-37}$ Conjugated forms of monomeric flavan-3-ols usually reach a $T_{\max }$ at $1.5 \mathrm{~h}$ after ingestion, which is characteristic of absorption in the small intestine. ${ }^{38}$

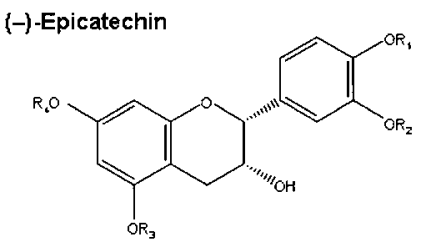<smiles>Oc1cc(O)c2c(c1)O[C@H](c1cc(O)c(O)c(O)c1)[C@H](O)C2</smiles>

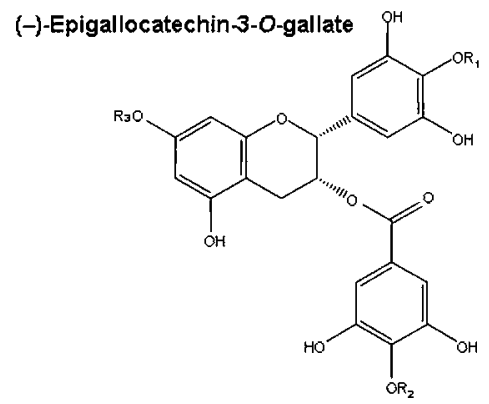

\begin{tabular}{|c|c|c|c|c|}
\hline Metabolite & $R_{1}$ & $R_{4}$ & $\overline{R_{8}}$ & $R_{4}$ \\
\hline EC-3'-aß-glucuronide & $\mathrm{H}$ & Gla & $H$ & $\mathrm{H}$ \\
\hline EC-5-O-OS-glusuronide & $\mathrm{H}$ & H & Gla & H \\
\hline EC-7-CB-glusuronide & $\mathrm{H}$ & $\mathrm{H}$ & $\mathrm{H}$ & Gla \\
\hline EC-7-Cosulfate & H & $H$ & H & softr \\
\hline EC-3'- - methyl & H & $\mathrm{CH}_{3}$ & $\mathrm{H}$ & $\mathrm{H}$ \\
\hline EC-4'-a methyl & $\mathrm{CH}_{3}$ & $\mathrm{H}$ & $\mathrm{H}$ & $\mathrm{H}$ \\
\hline EC-3'-amethyl-7-as-glucuronide & $\mathrm{H}$ & $\mathrm{CH}_{3}$ & $H$ & Gla \\
\hline EC-4'-a methyl-7-OB-glucuonide & $\mathrm{CH}_{3}$ & $\mathrm{H}$ & $H$ & Gla \\
\hline EC-4'-C-nethy|-5-O-O-g-gucuronide & $\mathrm{CH}_{3}$ & $\mathrm{H}$ & Gla & $\mathrm{H}$ \\
\hline
\end{tabular}

\begin{tabular}{|c|c|c|c|}
\hline Metabolite & $\mathbf{R}_{1}$ & $R_{2}$ & $R_{8}$ \\
\hline ESC-3:O-B-glucuronide & $\mathrm{H}$ & Gla & $H$ \\
\hline EGC-7-OB-glucuronise & $H$ & $H$ & Gla \\
\hline EGC-4-amethyl & $\mathrm{CH}_{3}$ & $\mathrm{H}$ & $\mathrm{H}$ \\
\hline EGC-4-amethyl-3-a-g-gluctuonide & $\mathrm{CH}_{3}$ & Gla & $\mathrm{H}$ \\
\hline 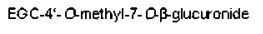 & $\mathrm{CH}_{3}$ & $\mathrm{H}$ & Gla \\
\hline EGC-4'- -methyl-3'-sulfate & $\mathrm{CH}_{3}$ & $\mathrm{H}$ & so, $\mathrm{H}$ \\
\hline
\end{tabular}

\begin{tabular}{|c|c|c|c|}
\hline Metabolite & $R_{1}$ & $\mathbf{R}_{\mathbf{2}}$ & $R_{3}$ \\
\hline EGCG-4',4"-di-Q-methyl & $\mathrm{CH}_{3}$ & $\mathrm{CH}_{3}$ & $\mathrm{H}$ \\
\hline$E \in \subset G-4 "-a$ methyl & H & $\mathrm{CH}_{3}$ & H \\
\hline EGCG-4"-O-B-glucuroride & $H$ & Gla & H \\
\hline 7-0-B-Bglucopyranosyl|-EGCG-4"-O-A & H & Glc & Gle \\
\hline
\end{tabular}

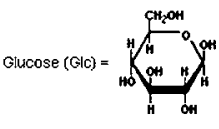

Fig. 2 Chemical structure of conjugated metabolites of (-)-epicatechin, (-)-epigallocatechin (EGC) and (-)-epigallocatechin-3-O-gallate (EGCG). 


\section{II.2 Absorption and metabolism of dimeric proanthocyanidins}

In the last decade, the absorption and metabolism of dimeric proanthocyanidins have been a subject of speculation. It was first thought that procyanidins could be depolymerized into bioavailable monomers under the acidic conditions of the stomach, ${ }^{39}$ but later studies failed to demonstrate this occurrence in vivo. ${ }^{40-42}$ In contrast to monomers, glucuronidated or sulfated metabolites of dimeric procyanidins have not been detected in biological fluids, ${ }^{43}$ although some methylated forms have been reported. ${ }^{44}$ Procyanidins B1 [epicatechin- $(4 \beta \rightarrow 8)$-catechin] and B2 [epicatechin- $(4 \beta \rightarrow 8)$-epicatechin] have been detected in their intact form at very low levels in human plasma (nM range) after consumption of $\operatorname{cocoa}^{45}$ or grape seeds, ${ }^{46}$ and present the lowest $C_{\text {max }}$ in plasma among flavonoid compounds. ${ }^{13}$ Besides dimer B2, procyanidin B5 (epicatechin- $(4 \beta \rightarrow 6)$-epicatechin) has also been detected in the plasma of rats fed cocoa extracts, ${ }^{47,48}$ but it was not detected in human plasma after cocoa consumption. ${ }^{45}$ However, dimer B3 [catechin- $(4 \alpha \rightarrow 8)$-catechin] and trimer C2 [catechin- $(4 \alpha \rightarrow 8)$-catechin- $(4 \alpha \rightarrow 8)$-catechin] were not detected in the plasma of rats fed the corresponding purified compounds. ${ }^{49}$ Recently, oligomers with DP 2-5 have been detected in rat plasma after the administration of apple procyanidin fractions $(1 \mathrm{~g} / \mathrm{kg}$ weight $)$ with the same DP. ${ }^{44}$

\section{Microbial catabolism of monomeric flavan-3-ols and proanthocyanidins}

It has been estimated that $90-95 \%$ of dietary polyphenols are not absorbed in the small intestine and therefore accumulate in the colon. ${ }^{50}$ In the case of flavan-3-ols, in studies performed with ileostomy patients (i.e. patients whose colon has been removed surgically), it was calculated that approximately $70 \%$ of the ingested monomeric flavan-3-ols from green tea could pass from the small to the large intestine, with $33 \%$ corresponding to the intact parent compounds. ${ }^{29}$ Recently, it has been reported that after oral administration of $\left[{ }^{14} \mathrm{C}\right]$ procyanidin $\mathrm{B} 2,63 \%$ of the total radioactivity was excreted via urine, indicating that a large quantity of the parent compound is degraded by the gut microflora. ${ }^{51}$ The recognition that the colon is a very active organ for the metabolism of flavan-3-ols, particularly proanthocyanidins, has led to a resurgence in the study of the biotransformation of these compounds and other polyphenols by the intestinal

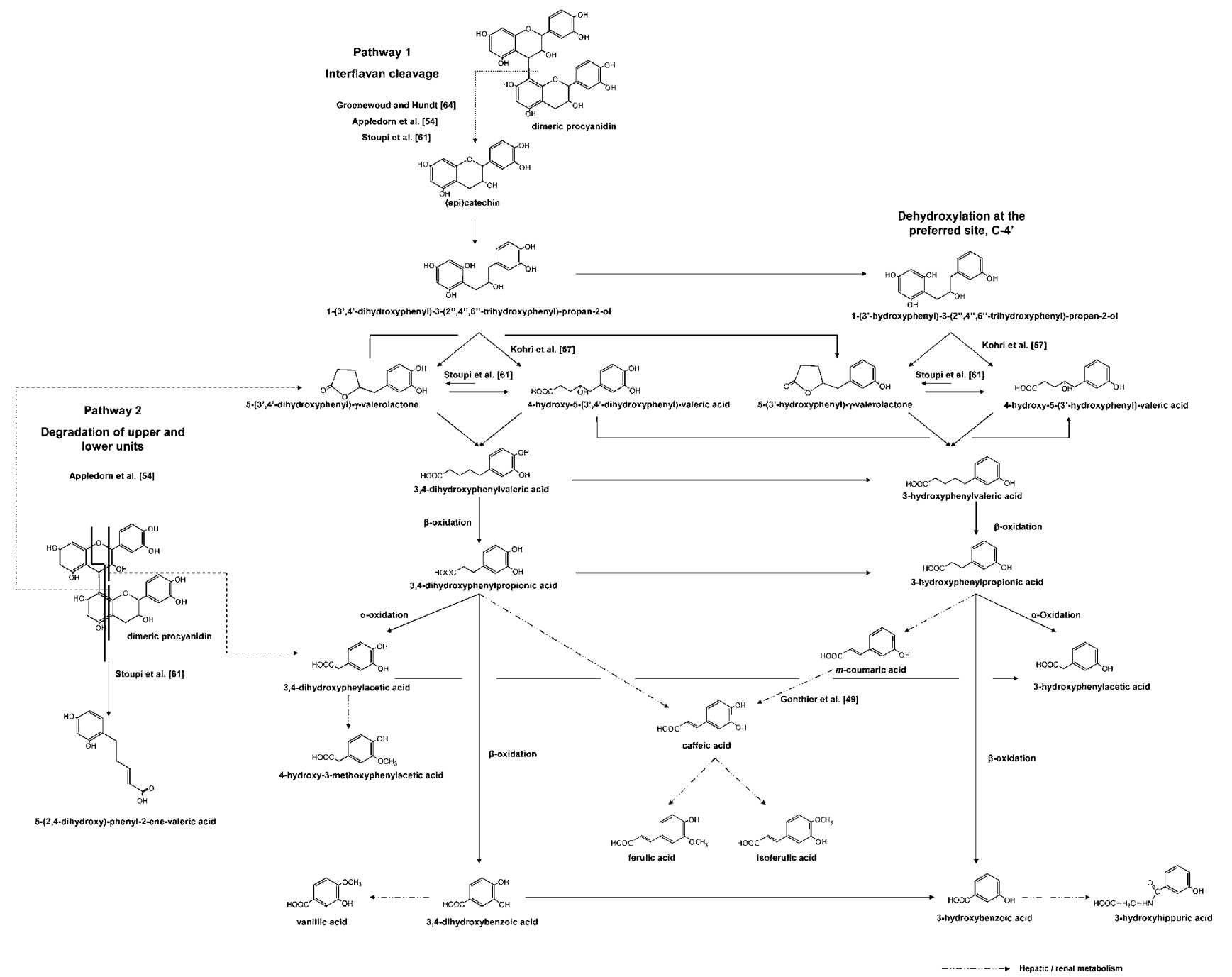

Fig. 3 Metabolic pathway tentatively proposed for the catabolism of monomeric flavan-3-ols and dimeric procyanidins by the intestinal microbiota. 
microbiota ${ }^{8,10}$ and their implication in the overall bioavailability and bioactivity of polyphenols.

\section{III.1 First steps of the catabolism of flavan-3-ols: formation of hydroxyphenylvalerolactones and valeric acids}

The complex catabolism of B-type proanthocyanidins involves C-ring opening, followed by lactonization, decarboxylation, dehydroxylation, and oxidation reactions, among others. ${ }^{10}$ Although numerous in vitro fermentation and in vivo studies have been carried out in recent years, the accumulated knowledge has only led to partial elucidation of the catabolic route of monomeric and B-type dimeric structures ${ }^{49,52-55}$ (Fig. 3). In the case of galloylated monomeric flavan-3-ols (ECG and EGCG), the microbial catabolism usually starts with the rapid cleavage of the gallic acid ester moiety by microbial esterases, giving rise to gallic acid which is further decarboxylated into pyrogallol. ${ }^{56-58}$ The C-ring is subsequently opened, giving rise to diphenylpropan-2ol, which is later converted into 5-( $3^{\prime}, 4^{\prime}$-dihydroxyphenyl)- $\gamma$ valerolactone (in the case of (epi)catechins) or 5 - $\left(3^{\prime}, 4^{\prime}, 5^{\prime}\right.$-trihydroxyphenyl)- $\gamma$-valerolactone (in the case of (epi)gallocatechins). ${ }^{56,58,59}$ The valerolactone ring later breaks, giving rise to 5-(3',4'-dihydroxyphenyl)valeric acid and/or 4-hydroxy-5-(3', 4'-dihydroxyphenyl)valeric acid. The identification of this latter compound was firstly proposed by Khori et al. ${ }^{57}$ and recently confirmed by Llorach et $a l^{60}$ in urine samples collected after cocoa consumption in humans, as well as by Stoupi et al. ${ }^{61}$ after in vitro fermentations carried out with human faeces in the presence of (-)-epicatechin and procyanidin B2.

Although it was first proposed that 4-hydroxy-5-(hydroxyphenyl)valeric acids could arise from the degradation of diphenylpropan-2-ols, concurrently with hydroxyphenyl- $\gamma$ valerolactones $^{57}$ (Fig. 3), it has recently been suggested that they are formed instead from hydroxyphenyl- $\gamma$-valerolactones, and that an interconversion between both forms [4-hydroxy-5(hydroxyphenyl)valeric acids and 5-(hydroxyphenyl)- $\gamma$-valerolactones] may exist, but is largely displaced towards the formation of the formers. ${ }^{61}$ Subsequent biotransformations of these valeric acids give rise to hydroxyphenylpropionic and hydroxybenzoic acids by successive loss of carbon atoms from the side chain through $\beta$-oxidation. ${ }^{56}$

\section{III.2 Metabolites arising from the catabolism of dimeric procyanidins}

The possible formation of 3,4-dihydroxyphenylacetic acid via $\alpha$ oxidation of 3,4-dihydroxyphenylpropionic acid (as described for tyrosine ${ }^{49,62}$ ) in the microbial catabolism pathway of monomeric flavan-3-ols, has been widely debated. Firstly, it was thought that 3,4-dihydroxyphenylacetic acid was only characteristic of the catabolism of dimeric procyanidins; ${ }^{63}$ however, other authors have recently proposed $\alpha$-oxidation as a possible pathway for the formation of this compound in the case of both monomers and dimers, ${ }^{61}$ without discarding other possible pathways, as proposed by Appeldoorn et al. ${ }^{54}$ in the case of dimers. According to these latter authors, 3,4-dihydroxyphenylacetic acid results from the cleavage of the upper unit of dimeric procyanidins, whereas the lower unit gives rise to $5-\left(3^{\prime}, 4^{\prime}-\right.$ dihydroxyphenyl)- $\gamma$-valerolactone and to the triggering of the rest of the previously described route (Fig. 3). The possible depolymerization of dimeric structures into monomeric units, firstly proposed by Groenewoud et al., ${ }^{64}$ has been recently confirmed to occur but to a lesser extent, ${ }^{54,61}$ representing less than $10 \%$ in the case of procyanidin B2. ${ }^{61}$ Other microbial metabolites arising exclusively from the catabolism of dimeric

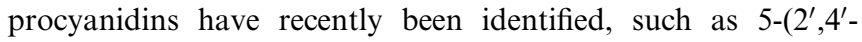
dihydroxyphenyl)-2-ene-valeric acid, as well as other compounds which have been tentatively identified as derivatives from the A-ring of the upper unit, including the interflavanic bond. ${ }^{61}$

\section{III.3 Last steps of the catabolism of flavan-3-ols}

Finally, the last steps of the microbial catabolism of (epi)catechin involve dehydroxylation of 3,4-dihydroxylated phenolic acids at C-4' (preferentially), and C-3', resulting in 3- and 4-monohydroxylated phenolic acids, respectively. ${ }^{53,61}$ In the case of (epi)gallocatechins, dehydroxylation preferentially occurs at C-5, resulting in 3,4-dihydroxylated phenolic acids which undergo further dehydroxylation at C-4 and C-3, as mentioned above. However, in the case of hydroxyphenylvalerolactones, the 3,5-dihydroxylated derivative arising from the dehydroxylation of 5 -( $\left(3^{\prime}, 4^{\prime}, 5^{\prime}\right.$-trihydroxyphenyl)- $\gamma$-valerolactone has also been identified, indicating that dehydroxylation at $\mathrm{C}-4^{\prime}$ occurs. ${ }^{20}$ Once absorbed, the microbial metabolites from flavan-3-ols are mainly metabolized in the liver by phase II enzymes as conjugated derivatives that are subsequently eliminated in urine. At the same time, a portion of microbial metabolites (non-conjugated microbial metabolites) is eliminated in the faeces.

Several microbe-derived metabolites that have been detected in urine in their actual conjugated form by targeted analysis

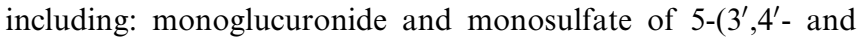
$3^{\prime}, 5^{\prime}$-dihydroxyphenyl)- $\gamma$-valerolactone, in addition to the methyl-sulfate derivatives of $5-\left(3^{\prime}, 4^{\prime}, 5^{\prime}\right.$-trihydroxyphenyl $)-\gamma$ valerolactone. $^{20,22,30,65}$ In the case of phenolic acids, monoglucuronide and monosulfate conjugates of mono- and di-hydroxyphenylpropionic and $p$-coumaric acids have been reported. ${ }^{66}$ Other reactions occurring in the liver and kidney include: glycine conjugation, dehydrogenation, hydroxylation and methylation. ${ }^{53}$ The excretion of microbial metabolites varies markedly between subjects, and for some individuals it may also vary with the substrate, reaching a very high proportion (up to $50 \%$ ) of the intake of polyphenols. ${ }^{8}$

\section{III.4 Main microbial phenolic metabolites found in urine}

Several feeding studies have revealed significant changes in the urinary excretion of microbe-derived phenolic acids after the intake of rich sources of flavan-3-ols. Among phenolic acids, mono- and di-hydroxylated phenylpropionic and phenylacetic acids, together with hydroxyhippuric acids, have been found as main urinary microbial phenolic acids derived from flavan-3-ol intake.

With regard to cocoa and cocoa-derived products, Gonthier et al. ${ }^{49}$ reported an increase in 3,4-dihydroxyphenylacetic and 3-hydroxyphenylacetic acids in urine after the administration of procyanidin B3 to rats. Similarly, Rios et al. ${ }^{67}$ reported a significant increase in the urinary excretion of these compounds, as well as in 3-hydroxyphenylpropionic and 3-hydroxybenzoic acids in 
healthy humans after acute consumption of flavanol-rich chocolate. Recently, Urpi-Sarda et $a l^{68}$ also found increased urinary levels of 3,4-dihydroxyphenylacetic and 3-hydroxyphenylacetic acids in humans after chronic consumption of cocoa powder with milk. Other studies have reported an increased urinary excretion of 3-hydroxypropionic and 3-hydroxyphenylacetic acids after human consumption of grape seed polyphenols. ${ }^{69}$ In the case of green tea, 3-hydroxyphenylpropionic and 4-hydroxyphenylacetic and 4-hydroxyphenylacetic acids significantly increased in human urine. $^{58}$ Finally, 3-hydroxyphenylpropionic and 3-hydroxybenzoic acids were also reported to increase in the urine of rats fed wine polyphenols. ${ }^{53}$

Besides these phenolic acids, which are also common to the microbial catabolism of other flavonoids, ${ }^{10} 5$ - $\left(3^{\prime}, 4^{\prime}, 5^{\prime}\right.$-trihydroxyphenyl)- $\gamma$-valerolactone and 5-( $3^{\prime}, 4^{\prime}$-dihydroxyphenyl)- $\gamma$-valerolactone are considered important microbial metabolites and potential biomarkers of flavan-3-ol consumption in humans, as has been confirmed after the intake of green tea, ${ }^{20,22,23,58}$ cocoa products $^{30}$ and almond skins. ${ }^{65,70}$

\section{Intestinal bacteria with ability to catabolize flavan-3-ols}

It is important to mention that the above difference of opinions concerning the possible catabolic route of monomeric and dimeric flavan-3-ols could be partly attributed to differences in the microbiota composition of faecal samples used in the different studies, suggesting that different pathways could coexist or one predominate over the others, depending on the catabolic capacity of the microbiota. An important limitation in this area is that bacteria belonging to human microbiota with the capacity to catabolize flavan-3-ols have still not been identified. To date, only bacteria with the capacity to catabolize other types of flavonoid compounds, mainly flavonols and flavones, have been described. These bacteria, in general, belong to the Clostridium and Eubacterium groups. ${ }^{10}$

Among the factors that may limit the identification of flavan3-ol catabolic bacteria, it is important to highlight the wellknown growth inhibitory effects of proanthocyanidins. Another factor that deserves consideration is the structural features of flavan-3-ols as complex non-planar molecules.

\section{IV.1 Inhibitory effects of proanthocyanidins and "tannin- resistant" bacteria}

The growth-inhibitory effects of proanthocyanidins on bacteria have been reviewed by Smith et al. ${ }^{71}$ Tannins are capable of complexing with polymers and minerals, making nutrients unavailable. In addition, they could have a direct effect by interacting with membranes, cell walls, and/or extracellular proteins. "Tannin-resistant" bacteria have been defined as those bacteria that are able to withstand the inhibitory effect of tannins. "Resistance" implies that some action is required on the part of the organism to withstand the inhibitory effect of tannins, including inducible adaptation or even gene transfer. ${ }^{71}$ Tanninresistance may also depend on the tannin concentration, structural composition and DP. It is important to highlight the fact that bacteria which are predominant in tannin-rich mediums may not be resistant per se, but are less affected by nutrient limitations or are better able to access limiting nutrients.

"Tannin-resistant" Gram-negative species (Enterobacteriaceae and Bacteriodes) have been isolated from rat faecal samples after prolonged administration of condensed tannins from Acacia angustissima, a forage legume. ${ }^{72}$ "Tannin-resistant" Gram-positive bacteria have also been identified. Brooker et al. ${ }^{73}$ isolated a Streptococcus strain (named $S$. caprinus and close to $S$. bovis) from the rumen of goats which was able to grow at $2.5 \%$ of condensed tannins. A Streptococcus strain (close to S. bovis and $S$. gallolyticus) has also been isolated from the rumen of sheep, goats and deer. ${ }^{74}$ Later, Molina et al. ${ }^{75}$ has also isolated a Eubacterium strain (close to E. cellulosolvens) from the rumen of moose, able to tolerate $0.5 \mathrm{~g} / \mathrm{L}$ of condensed tannins.

Some mechanisms by which bacteria can overcome inhibition by tannins include: modification/degradation of the substrate, dissociation of tannin-substrate complexes, cell membrane modification/repair and metal ion sequestration. It has been reported that Bifidobacterium infantis and Lactobacillus acidophilus are not inhibited by tannins because lactic acid bacteria do not require iron as they do not depend on metal-chelating enzymes, in particular heme enzymes. ${ }^{76}$ Moreover, in vivo studies have revealed that consumption of grape seed extract, containing $40 \%$ of condensed tannins, produced an increase in the bifidobacteria population in healthy individuals. ${ }^{77}$ Although tannin resistance is the first step in order for bacteria to metabolize condensed tannins, resistance does not guarantee metabolic activity, and the biodegradation pathway of "tannin-resistant" bacteria has not yet been described.

\section{IV.2 Structural features of flavan-3-ols limiting bacterial catabolism}

There is some evidence that the structural characteristics and stereochemistry of flavan-3-ols could be limiting factors for intestinal bacteria to be able to degrade these types of compounds. It has been reported that Eubacterium ramulus was unable to degrade (+)-catechin because of the absence of a functional group at C-4 in this flavonoid structure. ${ }^{78}$ Similarly, the human bacterium Eubacterium sp. (SDG-2) was able to open the ring of the $3 R[(-)$-catechin and (-)-epicatechin] and the $3 S$ $[(+)$-catechin and (+)-epicatechin] forms of monomeric flavan-3ols into 1,3-diphenylpropan-2-ols (Fig. 3), but was incapable of producing the same fission in their galloylated esters. ${ }^{79}$ However, in no instance was this bacteria able to continue the catabolism up to the formation of 5-(3',4'-dihydroxyphenyl)- $\gamma$-valerolactone. Another characteristic of this bacterium was the ability to dehydroxylate the $\mathrm{OH}$ groups in the $\mathrm{B}$ ring of 1,3-diphenylpropan-2-ols, but only of the $R$ forms. ${ }^{79}$ This fact, together with the inability to catabolize the gallate esters, suggests that the spatial configuration of both the original flavan-3-ol molecule and intermediate metabolites may limit the microbial degradation of flavan-3-ols. In fact, in a recent in vitro fermentation study with human faeces it was found that $(+)$-catechin $(2 R, 3 S)$ was firstly converted into (+)-epicatechin $(2 S, 3 S)$ by intestinal microbiota in order for the biotransformation process to proceed. ${ }^{80}$

Taken together, these findings suggest that it may be difficult to identify a single bacterium capable of exhibiting the 
whole catabolic pathway proposed in Fig. 3, but rather the catabolism may be carried out by different bacteria with specific catabolic activities that work in sequential form on the appearance of the different intermediate metabolites. Among the different phases of the catabolic pathway, formation of 5 -( $3^{\prime}, 4^{\prime}$-dihydroxyphenyl)- $\gamma$-valerolactone seems to be a limiting step.

\section{Bioactivity of flavan-3-ol metabolites}

As a consequence of their extensive metabolism in the human organism, the original flavan-3-ol structures present in food are not present in plasma and urine (with the exception of small amounts of gallate ester of monomeric flavan-3-ols and dimeric procyanidins that appear unmetabolized, as mentioned above) but rather appear as a complex series of phase II or tissular metabolites and, particularly, of microbe-derived phenolic metabolites. Therefore, both types of circulating metabolites should be responsible for the health benefits associated with the consumption of dietary sources rich in flavan-3-ols.

\section{V.1 Bioactivity of phase II or tissular metabolites derived from small-intestine and liver metabolism}

One of the limitations of many in vitro and ex vivo studies which have tried to unravel the health effects of flavan-3-ols has been the use of unconjugated structures, as well as the use of test concentrations (mM) at a much higher range than that found in biological fluids ( $\mu \mathrm{M}$ range). Taking this into consideration, this section will only try to cover the results of studies performed with conjugated metabolites in the micromolar or submillimolar range $(0.5-30 \mu \mathrm{M})$ found in plasma (Table 1$)$.

In general, the conjugation process (glucuronidation, sulfation and methylation) affects the physico-chemical properties of flavan-3-ols and, in turn, their residence in plasma, their excretion rate, and finally the bioactive properties of the parent compound. ${ }^{13}$ In particular, sulfation and glucuronidation involve a considerable attenuation of biological activity. The case of methylation seems to be more complex because the incorporation of methyl groups reduces the number of available $\mathrm{OH}$ groups, but at the same time increases the lipophilic nature of the compound, which can be advantageous for cellular uptake by passive diffusion. ${ }^{13}$

Antioxidant activity. The antioxidant activity of flavonoid metabolites has been widely studied, considering the fact that oxidative stress is implicated in the initiation and progression of chronic diseases. In the case of flavonoid compounds (i.e. quercetin), it has been observed that glucuronidation at C-3 and $\mathrm{C}-4^{\prime}$ of the $\mathrm{B}$ ring (catechol-type structure) produces a greater loss of antioxidant capacity than when it occurs at $\mathrm{C}$ 3 of the $\mathrm{C}$ ring. ${ }^{81-83}$ In contrast, glucuronidation at C-7 (A ring) seems to produce a slight increase in antioxidant activity. ${ }^{83} \mathrm{In}$ the case of flavan-3-ol metabolites, (-)-epicatechin and its 7-Oglucuronide presented a similar delay of $\mathrm{Cu}^{2+}$-induced LDL oxidation, whereas the activities of the $3^{\prime}-O$-glucuronide and the $4^{\prime}$-O-methyl-3'-O-glucuronide were significantly lower. ${ }^{84}$ However, in the case of galloylated (epi)gallocatechins, the position of glucuronidation affected the anti-radical capacity against DPPH differently to the other flavonoids, since EGCG7-O-glucuronide and EGCG-4" $-O$-glucuronide (galloylation in the gallic acid ring) were less active than the aglycone, whereas the $3^{\prime}$ - and $3^{\prime \prime}$ - $O$-glucuronides showed the same activity as the aglycone. ${ }^{24}$ For non-galloylated (epi)gallocatechins, EGC-7-Oglucuronide and $-3^{\prime}-O$-glucuronide were more active than the aglycone. $^{24}$

In the case of $O$-methylation, Cren-Olivé et al. ${ }^{85}$ also reported that the catechol B-ring was also the active moiety of $(+)$-catechin, since the $3^{\prime}$ - and $4^{\prime}$ - $O$-methyl ethers and $3^{\prime}, 4^{\prime}$-di- $O$-methyl ether showed a much lower inhibition of $\mathrm{Cu}^{2+}$-induced LDL oxidation than the aglycone, but the activity was recovered when these positions were free, as in the 5,7-di- $O$-methyl analogue. The $\mathrm{C}-3^{\prime}$ and $\mathrm{C}-4^{\prime}-O$-methyl ethers of (-)-epicatechin also showed a lower inhibition of peroxynitrite-induced tyrosine nitration than the parent compound. ${ }^{86}$ Similarly, $O$-methylation at position $\mathrm{C}-3^{\prime}$ in (-)-epicatechin, (-)-epigallocatechin and (-)-epicatechin-3-O-gallate elicited a potential inhibition of lipid oxidation of canola oil in comparison to the aglycone. ${ }^{87}$ In a recent study, $\mathrm{C}-3^{\prime}$ and $\mathrm{C}-4^{\prime}-O$-methyl ethers of $(+)$-catechin and (-)-epicatechin showed a lower antioxidant capacity than the parent compound, as measured by the ferric-reducing power (FRAP) and by the ability to scavenge the $\mathrm{ABTS}^{+}$radical cation. ${ }^{88}$ Moreover, the antioxidant activity of these metabolites was found to be $\mathrm{pH}$ dependent, but significant radical scavenging activity was found to be retained at $\mathrm{pH} 7.4$, suggesting that they could act as potential antioxidants under physiological conditions. $^{88}$

Vascular effects. Epicatechin and its metabolite, epicatechin-7$O$-glucuronide, have been identified as independent predictors of the vascular effects observed after flavanol-rich cocoa intake. ${ }^{19}$

Anti-inflammatory effects. In the case of EGCG metabolites, glucuronidation at C-7 affected the ability to inhibit the production of NO or the arachidonic acid metabolism in HT29 cells compared to the aglycone, but it was not affected in the case of glucuronidation at C-3', C- $3^{\prime \prime}, \mathrm{C}-4^{\prime \prime} .{ }^{24}$ Conversely, in the case of ECG, glucuronidation at C- $3^{\prime}$ decreased such capacity by $20 \%$ compared to the aglycone, but it was not affected in the case of the 7-O-glucuronide. ${ }^{24}$

Inhibition of cellular growth. The effectiveness of (-)-epicatechin metabolites on the inhibition of cellular growth has been studied in various types of cell lines. In the case of neuronal cells, it has been reported that $3^{\prime}-O$-methyl-epicatechin was as effective as (-)-epicatechin in the inhibition of apoptosis induced by oxidized LDL. ${ }^{89}$ Similarly, it has been reported that $3^{\prime}$ - $O$-methylepicatechin was as efficient as (-)-epicatechin in protecting human fibroblasts against cell death induced by oxidative stress. ${ }^{90}$ In the case of galloylated flavan-3-ol metabolites, methylation at C-4' and C-4" in (-)-epigallocatechin-3- $O$-gallate (EGCG) produced a 50\% decrease in the growth-inhibitory and pro-apoptotic activities of murine osteoclasts, compared to EGCG. ${ }^{91}$ In another study, methylated derivatives of EGCG at positions $\mathrm{C}-4^{\prime \prime}$ and $\mathrm{C}-4^{\prime}-4^{\prime \prime}$ (dimethyl derivative) presented less inhibitory capacity than EGCG of the enzyme 20 S proteasome, which catalyzes the degradation of intracellular proteins and is associated with cancer. ${ }^{92}$ 


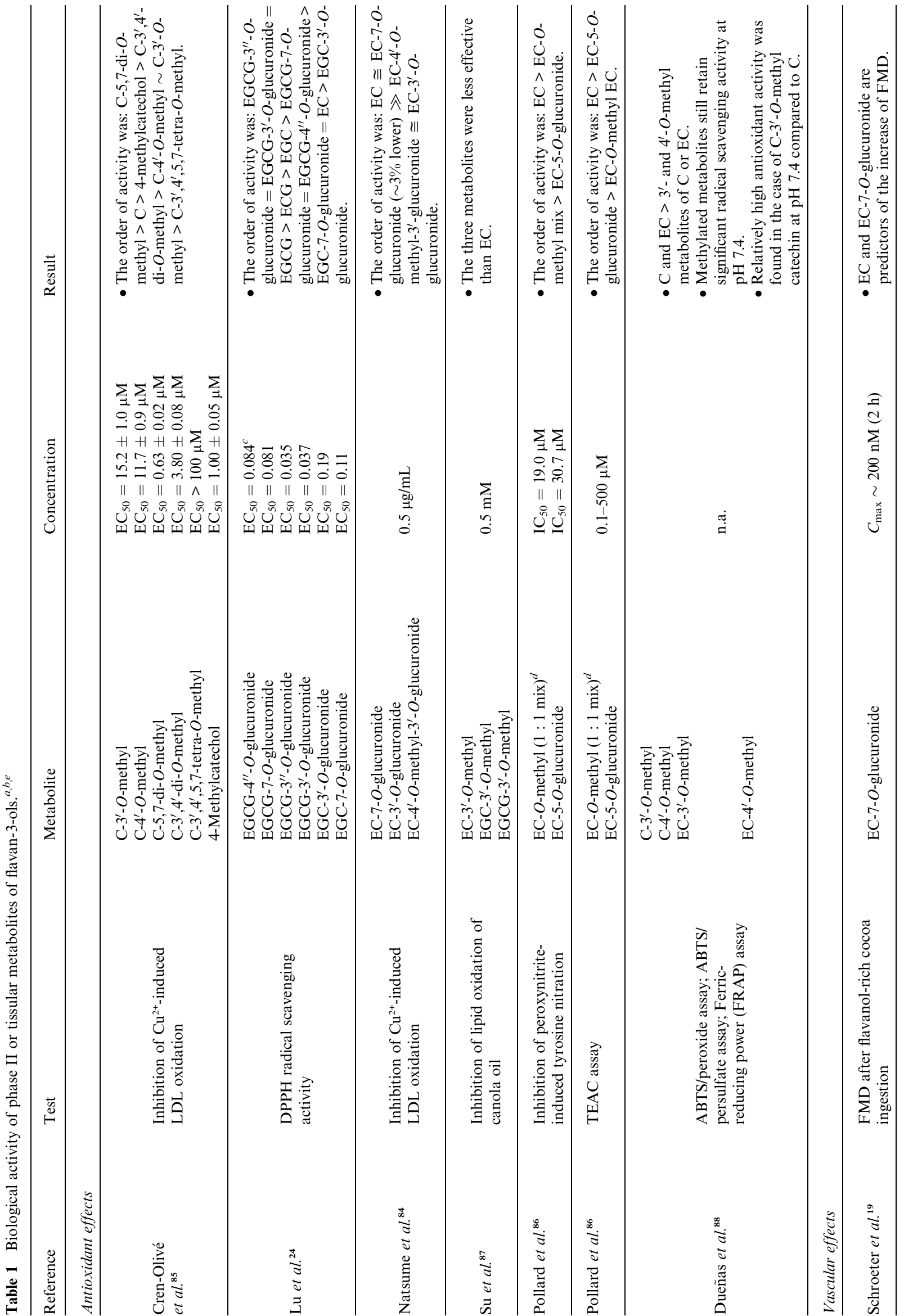




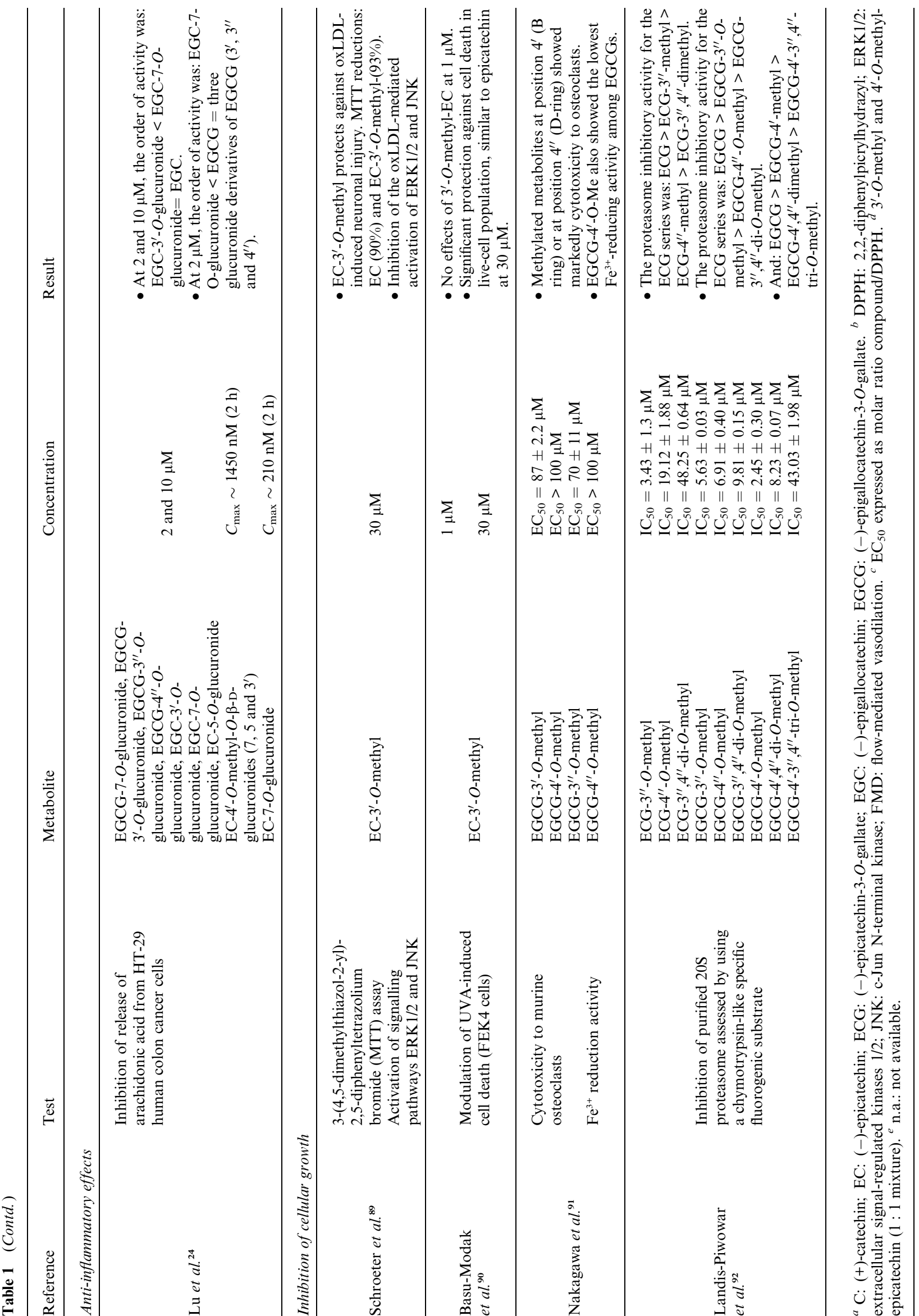




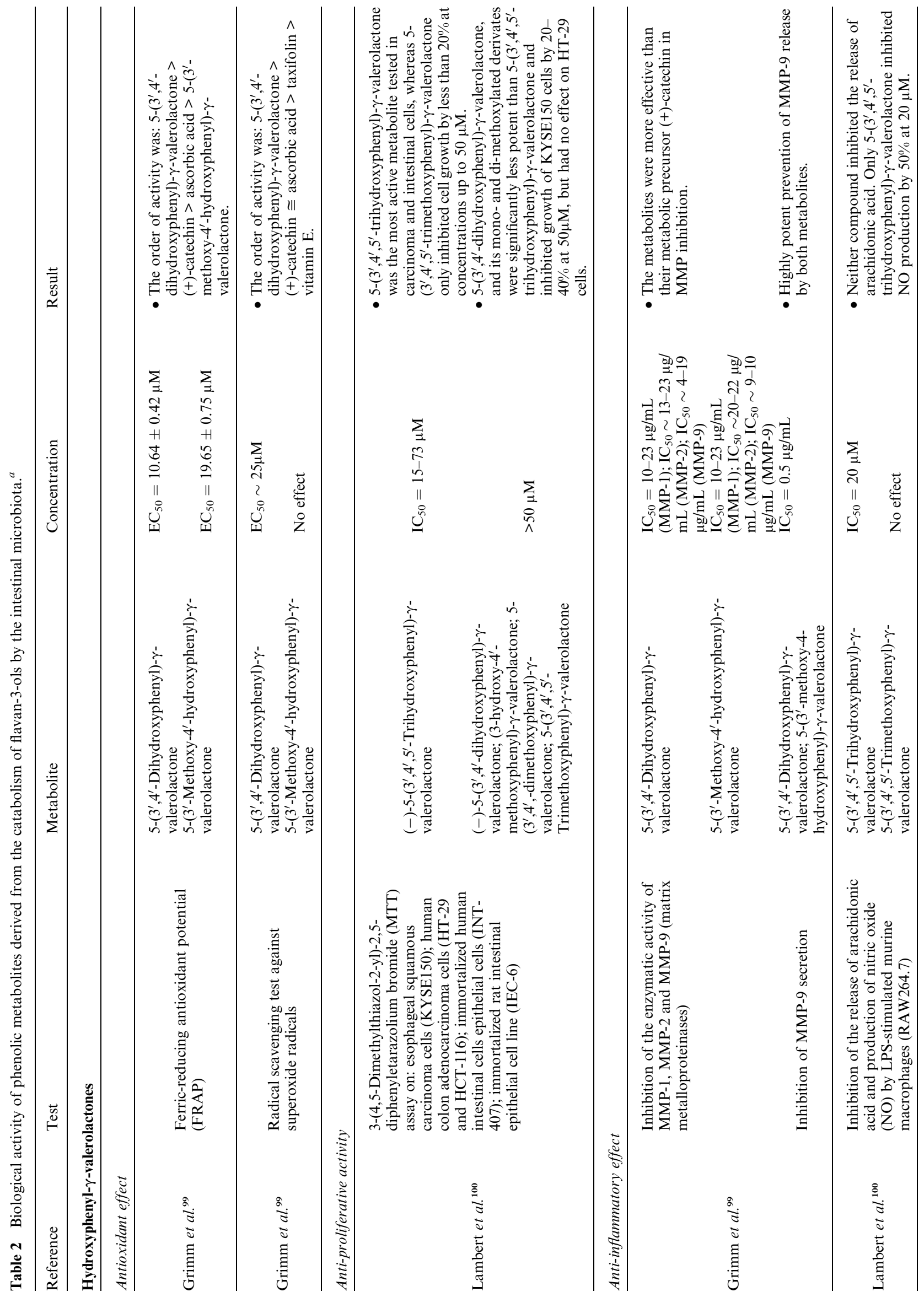




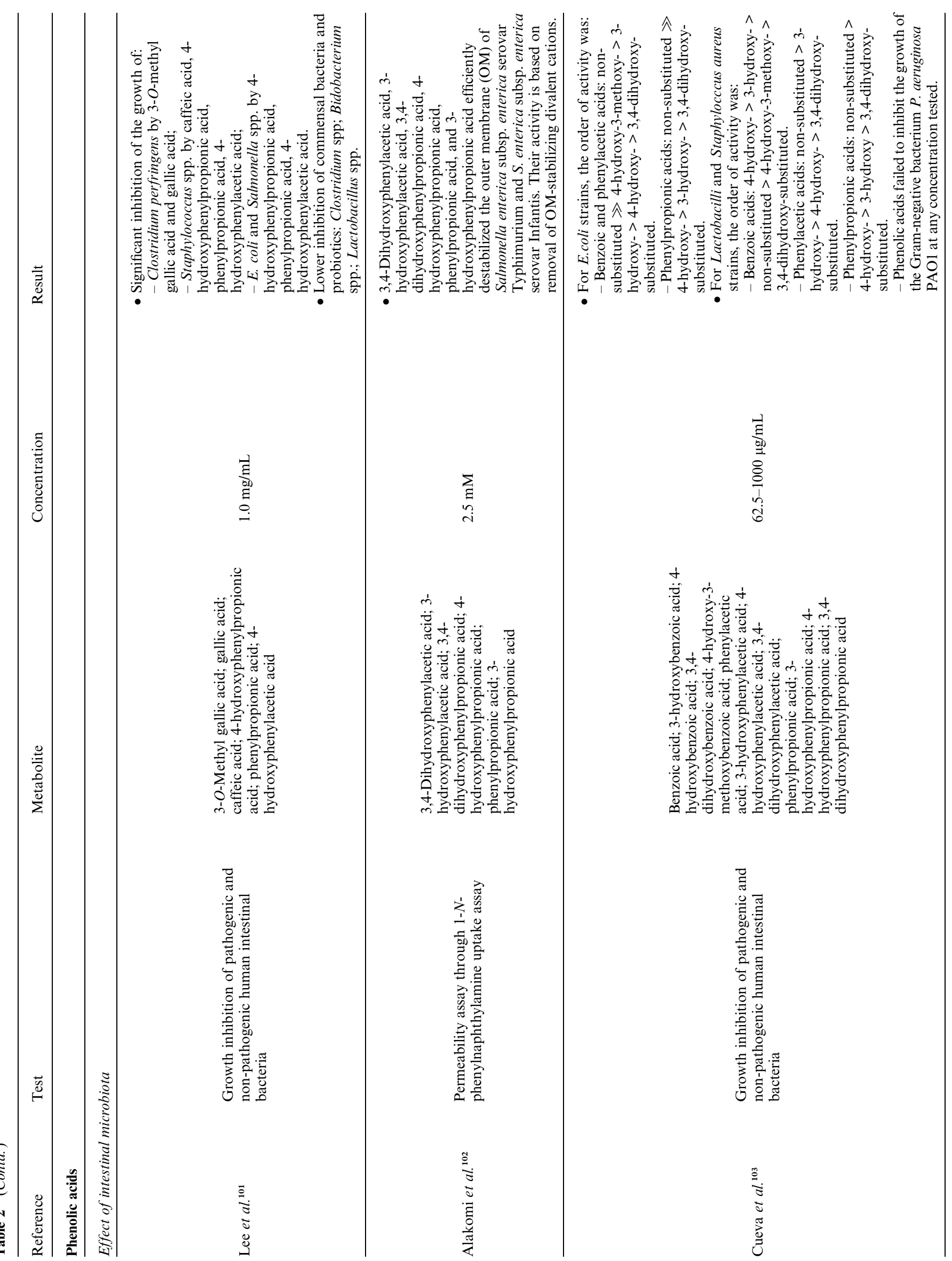




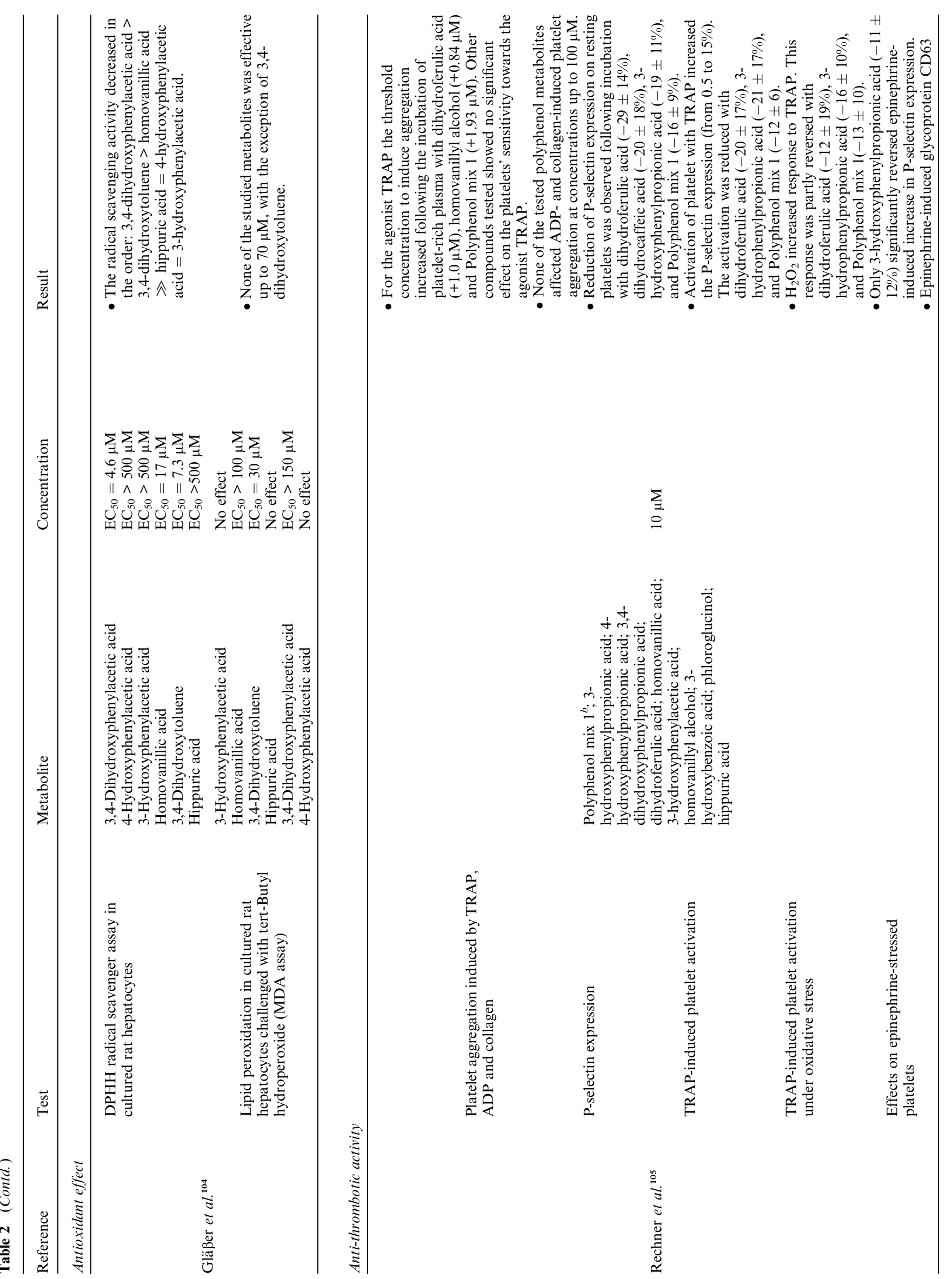



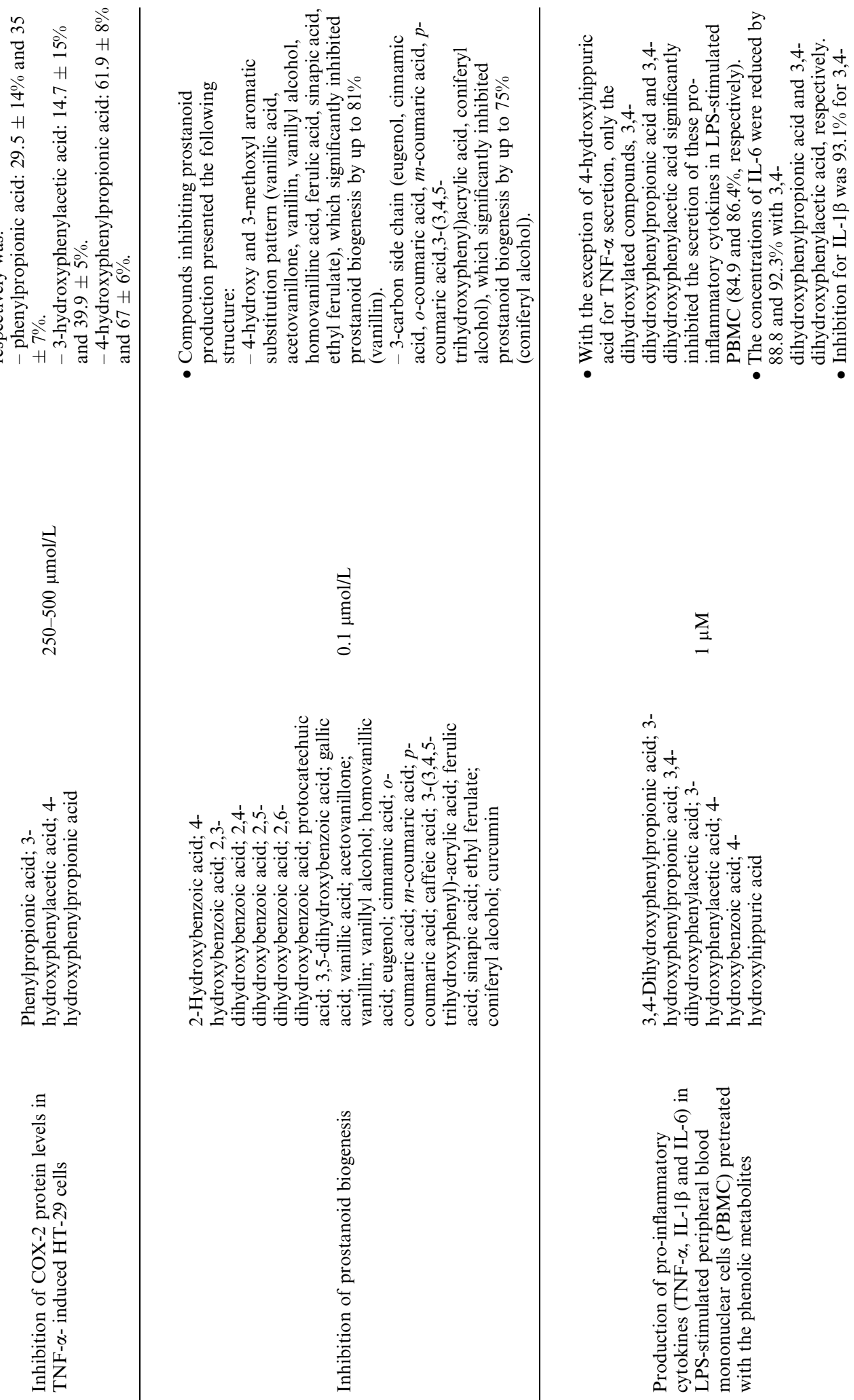

0
0
0
0
0
0
0
0
0
0
0
0
0
0
0
0
0
0
0
0
0
07
0

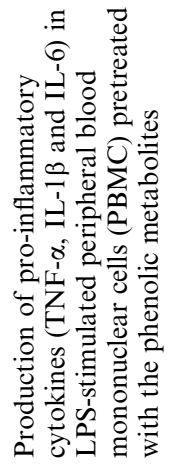

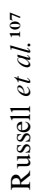

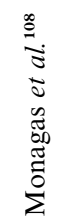




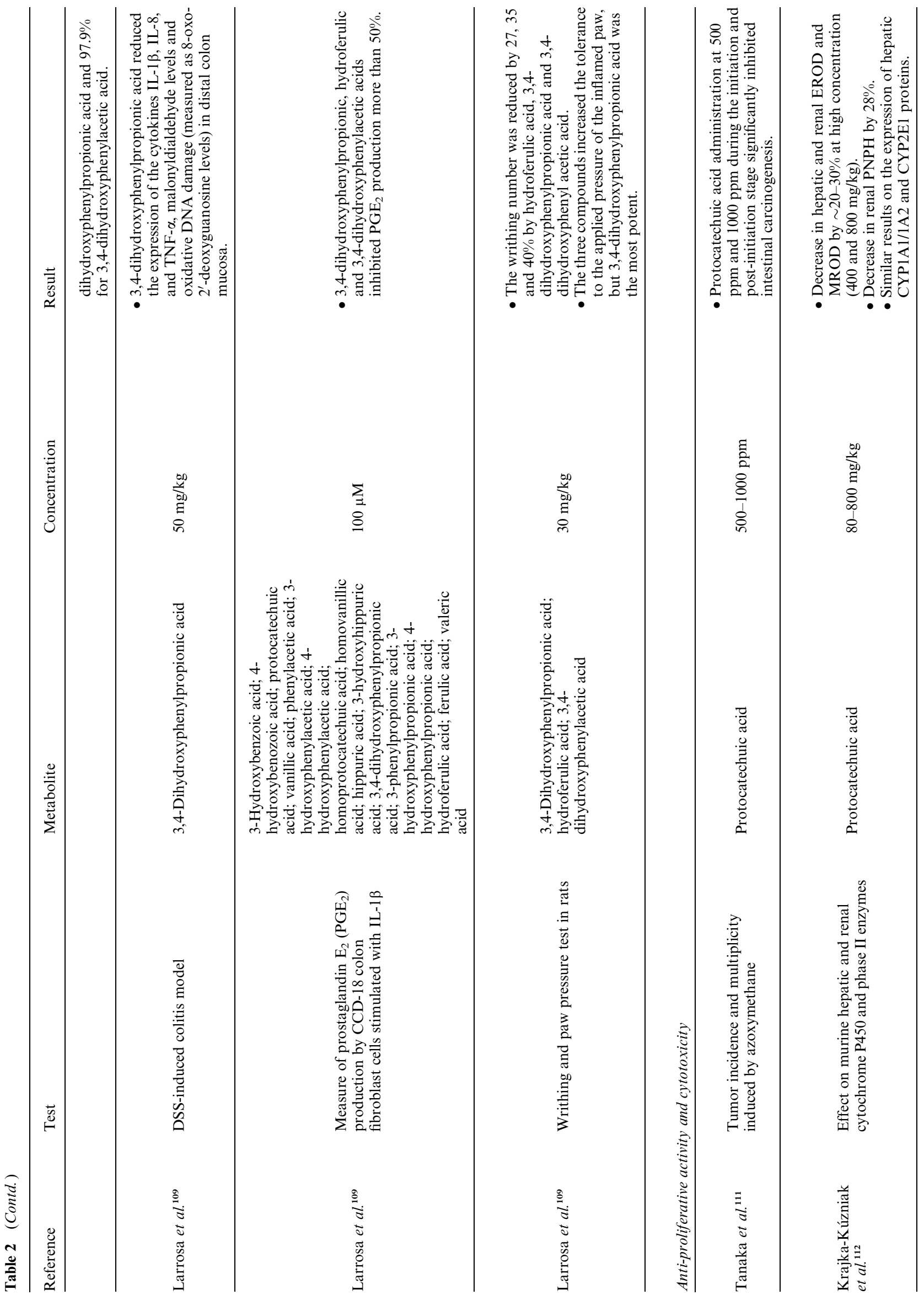




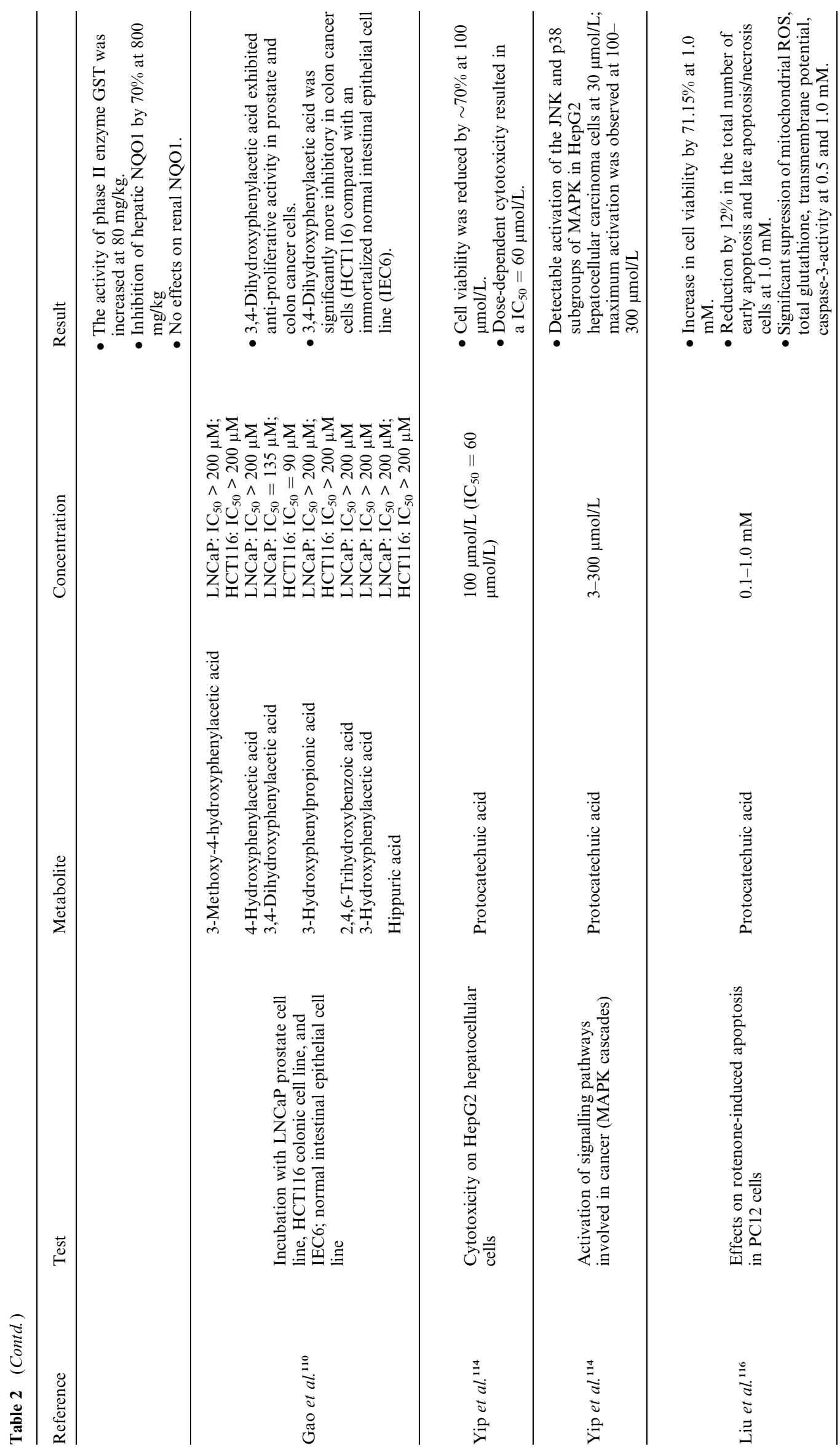




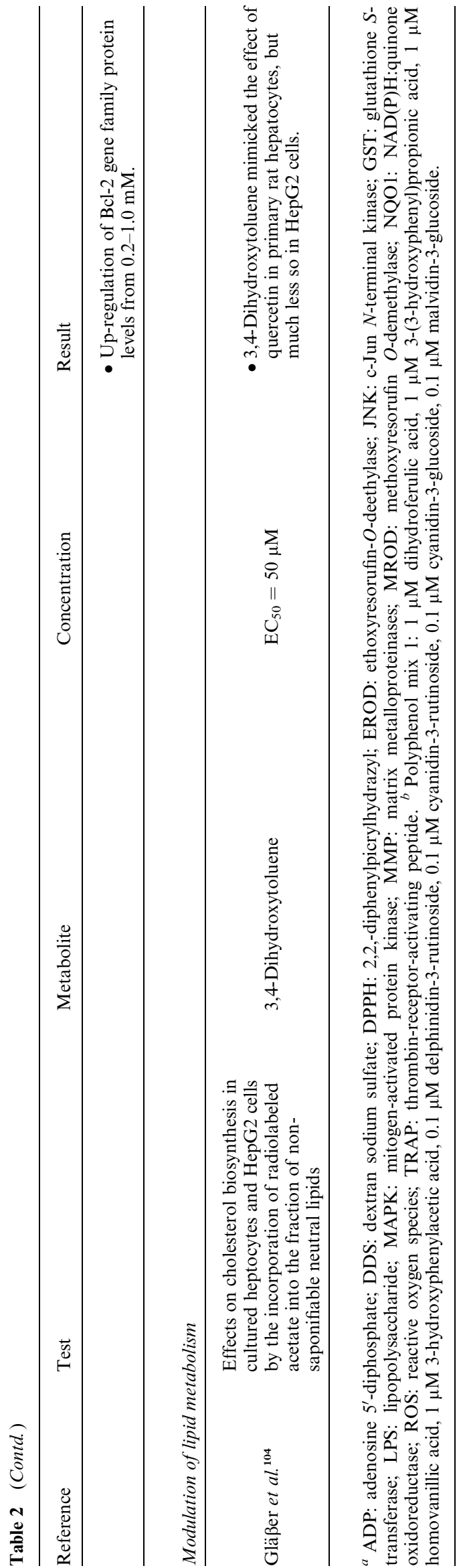

Interaction with cellular signalling pathways. In recent years, it has been suggested that polyphenols may exert their health effects via a mechanism of action beyond their antioxidant activity, and which is more related to its ability to generate an adaptive response at the cellular level that involves interaction with certain key proteins in triggering cell signalling pathways of oxidative stress and exposure to environmental toxins. ${ }^{9}$ In the case of flavan-3-ols, most studies have been performed mainly with the non-conjugated forms. It has been reported that EGCG induces apoptosis and causes cell-cycle arrest in tumor cells - but not in non-transformed normal cells - through the modulation of nuclear factor kappa-B $(\mathrm{NF}-\kappa \mathrm{B}) . \mathrm{NF}-\kappa \mathrm{B}$ is a redox-sensitive transcription factor which regulates the expression of proinflammatory cytokines, iNOS, COX-2, growth factors and inhibitors of apoptosis, and is related to inflammatory diseases (atherosclerosis, ulcerative colitis and rheumatoid arthritis), as well as neurodegenerative diseases and cancer. ${ }^{93,94}$ In another study, EGCG was also found to down-regulate NF- $\kappa \mathrm{B}$-inducing kinase (NIK), death-associated protein kinase (DPAK 1), and rho B and tyrosine protein kinase in PC-9 human lung cancer cells. ${ }^{95}$ A down-regulation of genes involved in a wide range of physiological functions was found in the mucosa of rats with induced colon carcinogenesis that had been fed wine polyphenols for 16 weeks, being the major pathways down-regulated those involved in the inflammatory response and steroid metabolism. ${ }^{96}$

With regards to genes involved in relevant process of atherosclerosis, red wine polyphenols were also found to significantly inhibit the proliferation of human vascular smooth muscle cells but not of human vascular endothelial cells - by reducing the promoter activity and expression of the cyclin A gene. ${ }^{97}$ Green tea polyphenols have been shown to modulate the regulation of the transcriptional expression of proatherogenic molecules, including the sterol-response element binding protein (SREBP), PPAR- $\gamma$, IL-8, and apoprotein-E. ${ }^{98}$

\section{V.2 Bioactivity of microbe-derived phenolic metabolites}

The biological activities of microbial metabolites derived from the catabolism of flavan-3-ols are still largely unknown, but in recent years those of hydroxyphenyl- $\gamma$-valerolactones, and especially of phenolic acids (di- and mono- hydroxylated phenylproponic, phenylacetic, benzoic acids and derivatives) formed from the subsequent catabolism of the former, have started to be unravelled. In contrast to phase II or tissular metabolites derived from small-intestine and liver metabolism as described above, to date, in vitro studies performed with microbe-derived phenolic metabolites have been carried out with unconjugated metabolites (with the exception of hippuric acids) (Table 2).

\section{V.2.1 Hydroxyphenyl- $\gamma$-valerolactones}

Antioxidant activity. The antioxidant activity of $5-\left(3^{\prime}, 4^{\prime}-\right.$ dihydroxyphenyl)- $\boldsymbol{\gamma}$-valerolactone and its methyl derivative 5-(3'-methoxy-4'-hydroxyphenyl)- $\gamma$-valerolactone has been tested against superoxide radicals, as well as by the ferricreducing antioxidant potential (FRAP) test. ${ }^{99}$ In the radical scavenging test, 5-( $3^{\prime}, 4^{\prime}$-dihydroxyphenyl)- $\gamma$-valerolactone was more effective than $(+)$-catechin, ascorbic acid and trolox, whereas 5-( $3^{\prime}$-methoxy- $4^{\prime}$-hydroxyphenyl)- $\gamma$-valerolactone did not exhibit antioxidant activity. In the reducing test, the order of 
values was: 5-(3,4-dihydroxyphenyl)- $\gamma$-valerolactone > $(+)$-catechin $>$ ascorbic acid $>$ 5-(3-methoxy-4-hydroxyphenyl)$\gamma$-valerolactone. ${ }^{99}$

Anti-proliferative activity. 5-(3',4',5'-Trihydroxyphenyl)- $\gamma$ valerolactone was more effective in the inhibition of the growth of a series of immortalized and malignant human cell lines than its trimethoxylated derivative, with the exception of HCT-116 colon cancer cells, and immobilized human (INT407) and rat (IEC-6) intestinal cells, which were not sensitive to the growth-inhibitory effects of this compound. ${ }^{100} 5-\left(3^{\prime}, 4^{\prime}, 5^{\prime}\right.$-Trihydroxyphenyl)- $\gamma$-valerolactone was also more effective in the inhibition of the growth of colon (HT-29) and oesophagus (KYSE150) cancer cells than 5-(3',4'-dihydroxyphenyl)- $\gamma$-valerolactone and its mono- and di-methoxylated derivatives. ${ }^{\mathbf{1 0 0}}$ However, the growth-inhibitory effects of this metabolite were lower than that of the aglycone, EGCG. Treatment of KYSE150 with 5-( $3^{\prime}, 4^{\prime}, 5^{\prime}$-trihydroxyphenyl)- $\gamma$-valerolactone at $50 \mu \mathrm{M}$ resulted in a $40 \%$ cell-growth inhibition after $48 \mathrm{~h}$, whereas EGCG resulted in a $50 \%$ inhibition at $20 \mu \mathrm{M} .{ }^{100}$

Anti-inflammatory effects. The inhibition of NO production in murine macrophage cells (RAW264.7) by 5-( $3^{\prime}, 4^{\prime}, 5^{\prime}$-trihydroxyphenyl)- $\gamma$-valerolactone and its trimethoxylated derivative has also been described. ${ }^{100}$ Whereas the former metabolite had $\mathrm{IC}_{50}=20 \mu \mathrm{M}$, the latter metabolite did not present any activity. However, none of the metabolites had inhibitory activity towards arachidonic acid metabolism in the same cell model. ${ }^{100}$ On the other hand, 5-( $3^{\prime}, 4^{\prime}$-dihydroxyphenyl $)-\gamma$-valerolactone and its methyl derivative 5-(3'-methoxy-4'-hydroxyphenyl)- $\gamma$ valerolactone had similar inhibitory activity of the enzymatic activity of matrix metalloproteinases (MMP-1, MMP-2 and MMP-9). ${ }^{99}$ Both metabolites also had similar efficacy in the inhibition of the secretion of MMP-9 from LPS-stimulated human monocytes. ${ }^{99}$

\section{V.2.2 Phenolic acids}

Effects on intestinal microbiota. Some phenolic acids, including 3-O-methyl gallic, gallic, caffeic, 4-hydroxyphenylpropionic, phenylpropionic, and 4-hydroxyphenylacetic acids derived from the microbial degradation of tea catechins, were able to inhibit the growth of several pathogenic and nonbeneficial intestinal bacteria without significantly affecting the growth of beneficial bacteria (Lactobacillus spp. and Bifidobacterium spp.). ${ }^{101}$ Other studies have revealed that dihydroxylated forms (i.e. 3,4-dihydroxyphenylacetic and 3,4-dihydroxyphenylpropionic acids) efficiently destabilize the outer membrane of Salmonella. ${ }^{102}$ Recently, Cueva et al. ${ }^{103}$ found that the number and position of substitutions in the benzene ring of phenolic acids and the saturated side chain length influenced the antimicrobial potential of phenolic acids against different microorganisms (Escherichia coli, Lactobacillus spp., Staphylococcus aureus, Pseudomonas aeruginosa and Candida albicans), although it was strain-dependent. In general, non-hydroxylated and monohydroxylated phenolic acids were more potent than dihydroxylated or disubstituted phenolic acids. With regard to the saturated side chain, the order of potency, for the same benzene ring-substitution, was benzoic $>$ phenylacetic $>$ phenylpropionic acid. Moreover, Lactobacillus spp. and S. aureus (Gram-positive) appeared more susceptible to the action of a series of microbial phenolic acids than Gram-negative bacteria, such as E. coli and P. aeruginosa. ${ }^{103}$

Antioxidant activity. Among a series of microbe-derived phenolic acids, 3,4-dihydroxyphenylacetic and 3,4-dihydroxytoluene exhibited the highest radical scavenging activity against DPPH in cultured rat hepatocytes. ${ }^{104}$ However, only the latter metabolite was found to be effective against the lipid peroxidation of rat hepatocytes challenged with tert-butyl-hydroperoxide. ${ }^{104}$

Anti-thrombotic activity. Rechner et al. ${ }^{105}$ studied the effect of several microbe-derived phenolic acids and their mixture on platelet function through several tests, including: platelet aggregation, P-selectin expression on resting platelets, effect on TRAP-induced platelet activation and epinephrine-stressed platelets. Dihydrocaffeic acid (3,4-dihydroxyphenylpropionic acid), dihydroferulic acid (4-hydroxy-3-methoxyphenylpropionic acid) and 3-hydroxyphenylpropionic acid, as well as the polyphenol mixture, were among the metabolites with the best activity in all tests performed. ${ }^{105}$

Anti-inflammatory activity. Studies carried out by Karlsson et al. ${ }^{106}$ showed that faecal samples containing microbial phenolic acids affected cyclooxygenase-2 (COX-2) protein levels in colon cancer cells (HT-29) stimulated with TNF- $\alpha$. Recently, Russell et al. ${ }^{107}$ reported that phenolic acids presenting 4-hydroxy-3-methoxy substitution and a one-carbon side chain such as vanillic acid and its derivatives (vanillin, vanillyl alcohol and acetovanillone), as well as a three-carbon side chain (cinnamic, $o-, m$ - and $p$-coumaric acid, and caffeic acid), inhibited cytokine-induced prostanoid biogenesis in human colonic fibroblasts. A structure-activity relationship has been observed between phenolic acids and their anti-inflammatory effects, since only dihydroxylated phenolic acids (i.e. 3,4-dihydroxyphenylpropionic and 3,4-dihydroxyphenylacetic acids) significantly inhibited the production of pro-inflammatory cytokines TNF- $\alpha$, IL-1 $\beta$, IL-6 in peripheral blood mononuclear cells (PBMC) stimulated with LPS, whereas no significant effect was found for the monohydroxylated ones. ${ }^{108}$ Similarly, Larrosa et al. ${ }^{109}$ recently found that these dihydroxylated phenolic acids provided the best inhibition of prostaglandin E2 production in cancer cells of fibroblast (CCD-18) stimulated with IL-1 $\beta$. In vivo experiments with rats have also shown that 3,4-dihydroxypropionic acid was the most potent metabolite in writhing and paw pressure tests in rodents and reduced the expression of cytokines TNF- $\alpha$, IL-1 $\beta$, IL- 8 , as well as the levels of malonaldehyde and oxidative damage to DNA in the distal mucosa of rats with dextran sodium sulfate (DSS)-induced colitis. ${ }^{109}$

Anti-proliferative activity and cytotoxicity. Among a series of microbial phenolic metabolites, 3,4-dihydroxyphenylacetic acid presented anti-proliferative activity in prostate ( $\mathrm{LNCaP})$ and, in particular, in colon cancer (HCT116) cells. ${ }^{110}$ In vivo studies have also revealed that protocatechuic acid reduces the incidence and multiplicity of cancerous tumors in the colon of rats. ${ }^{111}$ The modulation of cytochrome P450 and enzymes involved in xenobiotic activation and/or detoxification pathways (phase II 
enzymes) by protocatechuic acid in mouse liver and kidney has also been reported. ${ }^{112}$ Moreover, protocatechuic acid affected the level of rat hepatic and renal glutathione S-transferase (GST) isoenzymes. ${ }^{113}$ Cytotoxicity assays have also shown that protocatechuic acid effectively kill the HepG2 hepatocellular carcinoma cells by stimulating the c-Jun N-terminal kinase (JNK) and p38 subgroups of the mitogen-activated protein kinase (MAPK) family. ${ }^{14}$ A similar signalling pathway has been reported to be involved in the apoptosis of human gastric adenocarcinoma cells by protocatechuic acid. ${ }^{115}$ In a recent study, protocatechuic acid has also shown significant neuroprotective effects on retenoneinduced apoptosis in PC12 cells by ameliorating the mitochondrial dysfunction. ${ }^{\mathbf{1 1 6}}$

Modulation of lipid metabolism. It has been reported that 3,4dihydroxytoluene acid inhibits the synthesis of heptocellular cholesterol by inhibiting the incorporation of acetate into HepG2 liver cells. ${ }^{104}$

\section{Concluding remarks}

Over the last decade, a large number of epidemiological and interventional studies have demonstrated that there may be an association between flavonoid consumption and human health. Mechanistic studies trying to determine flavan-3-ol health effects have revealed that these polyphenols exhibit a wide range of biological effects. Despite the enormous effort devoted to this area, some results may be misleading, since polyphenol metabolism as xenobiotics has not been considered in a large number of studies which employed structural forms and concentration ranges not found in vivo. Therefore, polyphenol bioavailability is a key issue in the link between polyphenol and human health. In comparison to other micronutrients, knowledge about polyphenol bioavailability is advancing with the progress of analytical instrumentation which allows the identification of new metabolites in vivo. The recognition that some polyphenols, in particular proanthocyanidins, are extensively metabolized by the intestinal microbiota into low molecular weight compounds, and that these metabolites represent a very large percentage of the amount ingested, is bringing into consideration the inclusion of microbial metabolism as part of the bioavailability concept currently adopted for polyphenols. On the basis of these facts, interest is now focused on the study of the bioactivity of microbe-derived metabolites, in addition to phase II or tissular metabolites, as compounds responsible for the health effects of flavan-3-ols. Although advances are being made in the determination of the bioactivity of microbe-derived metabolites, most studies carried out until now have failed, again by not testing the conjugated forms found in vivo. With regards to the bioactivity of actual conjugated forms derived from flavan-3-ol in vivo metabolism, research carried out in the last decade has revealed that flavan-3-ols are multifunctional compounds that may display effects by mechanism(s) of action beyond their antioxidant activity.

The health effects derived from the interaction between flavan3-ols and the intestinal microbiota should be a subject of increasing interest. Although some authors have pointed out that polyphenols may be beneficial to gut health by increasing the population of potentially beneficial bacteria or exerting prebiotic actions, the effects that the interaction between flavan-3-ols and intestinal microbiota may have on the functionality of the metabolic activity of the microbiota and overall gastrointestinal health still remains largely unknown. In fact, for flavan-3-ols to function as a prebiotic, intestinal bacteria with such metabolic capacity should exist in the colon, but they are difficult to identify due to direct or indirect factors inherent in flavan-3-ols. The identification of flavan-3-ol-metabolizing bacteria and their possible use as a probiotic could be a good strategy for increasing the bioavailability and potential bioactivity of proanthocyanidins.

\section{Acknowledgements}

This work has been funded by the Spanish Ministry for Science and Innovation (AGL2009-13361-C02-01 and CSD2007-00063 Consolider Ingenio 2010 FUN-C-FOOD Projects), and the Comunidad de Madrid (ALIBIRD P2009/AGR-1469 Project). F.S.-P. is the recipient of a contract from the JAE-Doc Program (CSIC). I.G. was the recipient of a fellowship from the I3P Program funding by the European Social Fund. M.U-S. thanks the FPI fellowship from MICINN. R.L. thanks the "Fondo de Investigación Sanitaria" post-doctoral program (F.I.S. CD06/ 00161) from MICINN.

\section{References}

1 P. M. Aron and J. A. Kennedy, Flavan-3-ols: Nature, occurrence and biological activity, Mol. Nutr. Food Res., 2008, 52, 79-104.

2 S. Renaud and M. De Lorgeril, Wine, alcohol, platelets, and the French paradox for coronary heart disease, Lancet, 1992, 339, $1523-1526$

3 B. Buijsse, E. J. M. Feskens, F. J. Kok and D. Kromhout, Cocoa intake, blood pressure, and cardiovascular mortality: The Zutphen Elderly Study, Arch. Intern. Med., 2006, 166, 411-417.

4 G. L. Tipoe, T. M. Leung, M. W. Hung and M. L. Fung, Green tea polyphenols as an anti-oxidant and anti-inflammatory agent for cardiovascular protection, Cardiovasc. Hematol. Disord.: Drug Targets, 2007, 7, 135-144.

5 L. Gu, M. A. Kelm, J. F. Hammerstone, G. Beecher, J. Holden, D. Haytowitz, S. Gebhardt and R. L. Prior, Concentrations of proanthocyanidins in common foods and estimations of normal consumption, J. Nutr., 2004, 134, 613-617.

6 S. De Pascual-Teresa, C. Santos-Buelga and J. G. Rivas-Gonzalo, Quantitative analysis of flavan-3-ols in Spanish foodstuffs and beverages, J. Agric. Food Chem., 2000, 48, 5331-5337.

7 F. Saura-Calixto, J. Serrano and I. Goñi, Intake and bioaccessibility of total polyphenols in a whole diet, Food Chem., 2007, 101, 492-501.

8 A. M. Aura, Microbial metabolism of dietary phenolic compounds in the colon, Phytochem. Rev., 2008, 7, 407-429.

9 A. Crozier, I. B. Jaganath and M. N. Clifford, Dietary phenolics: Chemistry, bioavailability and effects on health, Nat. Prod. Rep., 2009, 26, 1001-1043.

10 M. V. Selma, J. C. Espín and F. A. Tomás-Barberán, Interaction between phenolics and gut microbiota: Role in human health, J. Agric. Food Chem., 2009, 57, 6485-6501.

11 D. Del Rio, L. G. Costa, M. E. J. Lean and A. Crozier, Polyphenols and health: What compounds are involved?, Nutr., Metab. Cardiovasc. Dis., 2010, 20, 1-6.

12 C. Manach, A. Scalbert, C. Morand, C. Rémésy and L. Jiménez, Polyphenols: Food sources and bioavailability, Am. J. Clin. Nutr., 2004, 79, 727-747.

13 J. L. Donovan, C. Manach, R. M. Faulks and P. A. Kroon, Absorption and metabolism of dietary plant secondary metabolites, in Plant secondary metabolites Occurrence, structure and role in the human diet, ed. A. Crozier, M. N. Clifford and $\mathrm{H}$. Ashihara, Blackwell Publishing Ltd, Oxford, UK, 2006, pp. 303-341. 
14 Z. Cheng, A. Radominska-Pandya and T. R. Tephly, Studies on the substrate specificity of human intestinal UDPglucuronosyltransferases 1A8 and 1A10, Drug Metab. Dispos., 1999, 27, 1165-1170.

$15 \mathrm{~J}$. B. Vaidyanathan and T. Walle, Glucuronidation and sulfation of the tea flavonoid (-)-epicatechin by the human and rat enzymes, Drug Metab. Dispos., 2002, 30, 897-903.

16 S. Baba, N. Osakabe, A. Yasuda, M. Natsume, T. Takizawa, T. Nakamura and J. Terao, Bioavailability of (-)-epicatechin upon intake of chocolate and cocoa in human volunteers, Free Radical Res., 2000, 33, 635-641.

17 M. Natsume, N. Osakabe, M. Oyama, M. Sasaki, S. Baba, Y. Nakamura, T. Osawa and J. Terao, Structures of (-)-epicatechin glucuronide identified from plasma and urine after oral ingestion of (-)-epicatechin: Differences between human and rat, Free Radical Biol. Med., 2003, 34, 840-849.

18 J. P. E. Spencer, M. M. Abd El Mohsen and C. Rice-Evans, Cellular uptake and metabolism of flavonoids and their metabolites: Implications for their bioactivity, Arch. Biochem. Biophys., 2004, 423, 148-161.

19 H. Schroeter, C. Heiss, J. Balzer, P. Kleinbongard, C. L. Keen, N. K. Hollenberg, H. Sies, C. Kwik-Uribe, H. H. Schmitz and M. Kelm, (-)-Epicatechin mediates beneficial effects of flavanolrich cocoa on vascular function in humans, Proc. Natl. Acad. Sci. U. S. A., 2006, 103, 1024-1029.

20 S. Sang, M. J. Lee, I. Yang, B. Buckley and C. S. Yang, Human urinary metabolite profile of tea polyphenols analyzed by liquid chromatography/electrospray ionization tandem mass spectrometry with data-dependent acquisition, Rapid Commun. Mass Spectrom., 2008, 22, 1567-1578.

21 S. Sang and C. S. Yang, Structural identification of novel glucoside and glucuronide metabolites of (-)-epigallocatechin-3-gallate in mouse urine using liquid chromatography/electrospray ionization tandem mass spectrometry, Rapid Commun. Mass Spectrom., 2008, 22, 3693-3699.

22 C. Li, X. Meng, B. Winnik, M. J. Lee, H. Lu, S. Sheng, B. Buckley and C. S. Yang, Analysis of urinary metabolites of tea catechins by liquid chromatography/electrospray ionization mass spectrometry, Chem. Res. Toxicol., 2001, 14, 702-707.

23 X. Meng, S. Sang, N. Zhu, H. Lu, S. Sheng, M. J. Lee, C. T. Ho and C. S. Yang, Identification and characterization of methylated and ring-fission metabolites of tea catechins formed in humans, mice, and rats, Chem. Res. Toxicol., 2002, 15, 1042-1050.

24 H. Lu, X. Meng, C. Li, S. Sang, C. Patten, S. Sheng, J. Hong, N. Bai, B. Winnik, C. T. Ho and C. S. Yang, Glucuronides of tea catechins: Enzymology of biosynthesis and biological activities, Drug Metab. Dispos., 2003, 31, 452-461.

25 E. Roura, C. Andrés-Lacueva, R. Estruch, M. L. M. Bilbao, M. Izquierdo-Pulido and R. M. Lamuela-Raventós, The effects of milk as a food matrix for polyphenols on the excretion profile of cocoa (-)-epicatechin metabolites in healthy human subjects, $B r$. J. Nutr., 2008, 100, 846-851.

26 F. A. Tomas-Barberán, E. Cienfuegos-Jovellanos, A. Marín, B. Muguerza, A. Gil-Izquierdo, B. Cerdá, P. Zafrilla, J. Morillas, J. Mulero, A. Ibarra, M. A. Pasamar, D. Ramón and J. C. Espín, A new process to develop a cocoa powder with higher flavonoid monomer content and enhanced bioavailability in healthy humans, J. Agric. Food Chem., 2007, 55, 3926-3935.

27 C. Auger, W. Mullen, Y. Hara and A. Crozier, Bioavailability of polyphenon E flavan-3-ols in humans with an ileostomy, J. Nutr., 2008, 138, 1535S-1542S.

28 A. Stalmach, S. Troufflard, M. Serafini and A. Crozier, Absorption, metabolism and excretion of Choladi green tea flavan-3-ols by humans, Mol. Nutr. Food Res., 2009, 53, S44-S53.

29 A. Stalmach, W. Mullen, H. Steiling, G. Williamson, M. E. J. Lean and A. Crozier, Absorption, metabolism, and excretion of green tea flavan-3-ols in humans with an ileostomy, Mol. Nutr. Food Res., 2010, 54, 323-334.

30 M. Urpi-Sarda, M. Monagas, N. Khan, R. Llorach, R. M. LamuelaRaventos, O. Jauregui, R. Estruch, M. Izquierdo-Pulido and C. Andres-Lacueva, Targeted metabolic profiling of phenolics in urine and plasma after regular consumption of cocoa by liquid chromatography-tandem mass spectrometry, J. Chromatogr., A, 2009, 1216, 7258-7267.
31 J. L. Donovan, V. Crespy, M. Oliveira, K. A. Cooper, B. B. Gibson and G. Williamson, (+)-Catechin is more bioavailable than (-)-catechin: Relevance to the bioavailability of catechin from cocoa, Free Radical Res., 2006, 40, 1029-1034.

32 M. J. Lee, P. Maliakal, L. Chen, X. Meng, F. Y. Bondoc, S. Prabhu, G. Lambert, S. Mohr and C. S. Yang, Pharmacokinetics of tea catechins after ingestion of green tea and (-)-epigallocatechin-3gallate by humans: Formation of different metabolites and individual variability, Cancer Epidemiol. Biomarkers Prevent., 2002, 11, 1025-1032.

33 C. S. Yang, M. J. Lee and L. Chen, Human salivary tea catechin levels and catechin esterase activities: Implication in human cancer prevention studies, Cancer Epidemiol. Biomarkers Prevent., 1999, 8, 83-89.

34 C. S. Yang, X. Meng, M. J. Lee, C. Li, S. Sheng, N. Zhu, S. Sang and C. T. Ho, Formation and identification of 4'-O-methyl(-)-epigallocatechin in humans, Drug Metab. Dispos., 2001, 29, 789-793.

35 H. H. S. Chow, Y. Cai, D. S. Alberts, I. Hakim, R. Dorr, F. Shahi, J. A. Crowell, C. S. Yang and Y. Hara, Phase I pharmacokinetic study of tea polyphenols following single-dose administration of epigallocatechin gallate and Polyphenon E, Cancer Epidemiol. Biomarkers Prevent., 2001, 10, 53-58.

36 U. Ullmann, J. Haller, J. P. Decourt, N. Girault, J. Girault, A. S. Richard-Caudron, B. Pineau and P. Weber, A single ascending dose study of epigallocatechin gallate in healthy volunteers, J. Int. Med. Res., 2003, 31, 88-101.

37 S. M. Henning, Y. Niu, Y. Liu, N. H. Lee, Y. Hara, G. D. Thames, R. R. Minutti, C. L. Carpenter, H. Wang and D. Heber, Bioavailability and antioxidant effect of epigallocatechin gallate administered in purified form versus as green tea extract in healthy individuals, J. Nutr. Biochem., 2005, 16, 610-616.

38 C. Manach, G. Williamson, C. Morand, A. Scalbert and C. Rémésy, Bioavailability and bioefficacy of polyphenols in humans. I. Review of 97 bioavailability studies, Am. J. Clin. Nutr., 2005, 81, 230S-242S.

39 J. P. E. Spencer, F. Chaudry, A. S. Pannala, S. K. Srai, E. Debnam and C. Rice-Evans, Decomposition of cocoa procyanidins in the gastric milieu, Biochem. Biophys. Res. Commun., 2000, 272, 236-241.

40 J. L. Donovan, C. Manach, L. Rios, C. Morand, A. Scalbert and C. Rémésy, Procyanidins are not bioavailable in rats fed a single meal containing a grapeseed extract or the procyanidin dimer B, Br. J. Nutr., 2002, 87, 299-306.

41 L. Y. Rios, R. N. Bennett, S. A. Lazarus, C. Rémésy, A. Scalbert and G. Williamson, Cocoa procyanidins are stable during gastric transit in humans, Am. J. Clin. Nutr., 2002, 76, 1106-1110.

42 C. Tsang, C. Auger, W. Mullen, A. Bornet, J. M. Rouanet, A. Crozier and P. L. Teissedre, The absorption, metabolism and excretion of flavan-3-ols and procyanidins following the ingestion of a grape seed extract by rats, Br. J. Nutr., 2005, 94, 170-181.

43 M. M. Appeldoorn, J. P. Vincken, H. Gruppen and P. C. H. Hollman, Procyanidin dimers A1, A2, and B2 are absorbed without conjugation or methylation from the small intestine of rats, J. Nutr., 2009, 139, 1469-1473.

44 T. Shoji, S. Masumoto, N. Moriichi, H. Akiyama, T. Kanda, Y. Ohtake and Y. Goda, Apple procyanidin oligomers absorption in rats after oral administration: Analysis of procyanidins in plasma using the porter method and high-performance liquid chromatography/tandem mass spectrometry, J. Agric. Food Chem., 2006, 54, 884-892.

45 R. R. Holt, S. A. Lazarus, M. Cameron Sullards, Q. Y. Zhu, D. D. Schramm, J. F. Hammerstone, C. G. Fraga, H. H. Schmitz and C. L. Keen, Procyanidin dimer B2 [epicatechin-(4ß-8)epicatechin] in human plasma after the consumption of a flavanolrich cocoa, Am. J. Clin. Nutr., 2002, 76, 798-804.

46 A. Sano, J. Yamakoshi, S. Tokutake, K. Tobe, Y. Kubota and M. Kikuchi, Procyanidin B1 is detected in human serum after intake of proanthocyanidin-rich grape seed extract, Biosci., Biotechnol., Biochem., 2003, 67, 1140-1143.

47 S. Baba, N. Osakabe, M. Natsume and J. Terao, Absorption and urinary excretion of procyanidin B2 [epicatechin-(4ß-8)epicatechin] in rats, Free Radical Biol. Med., 2002, 33, 142-148.

48 Q. Y. Zhu, R. R. Holt, S. A. Lazarus, J. L. Ensunsa, J. F. Hammerstone, H. H. Schmitz and C. L. Keen, Stability of the flavan-3-ols epicatechin and catechin and related dimeric 
procyanidins derived from cocoa, J. Agric. Food Chem., 2002, 50, $1700-1705$.

49 M. P. Gonthier, J. L. Donovan, O. Texier, C. Felgines, C. Remesy and A. Scalbert, Metabolism of dietary procyanidins in rats, Free Radical Biol. Med., 2003, 35, 837-844.

$50 \mathrm{M}$. N. Clifford, Diet-derived phenols in plasma and tissues and their implications for health, Planta Med., 2004, 70, 1103-1114.

51 S. Stoupi, G. Williamson, F. Viton, D. Barron, L. J. King, J. E. Brown and M. N. Clifford, In vivo bioavailability, absorption, excretion, and pharmacokinetics of [14C]procyanidin B2 in male rats, Drug Metab. Dispos., 2010, 38, 287-291.

52 S. Déprez, C. Brezillon, S. Rabot, C. Philippe, I. Mila, C. Lapierre and A. Scalbert, Polymeric proanthocyanidins are catabolized by human colonic microflora into low-molecular-weight phenolic acids, J. Nutr., 2000, 130, 2733-2738.

53 M. P. Gonthier, V. Cheynier, J. L. Donovan, C. Manach, C. Morand, I. Mila, C. Lapierre, C. Rémésy and A. Scalbert, Microbial aromatic acid metabolites formed in the gut account for a major fraction of the polyphenols excreted in urine of rats fed red wine polyphenols, J. Nutr., 2003, 133, 461-467.

54 M. M. Appeldoorn, J. P. Vincken, A. M. Aura, P. C. H. Hollman and H. Gruppen, Procyanidin dimers are metabolized by human microbiota with 2-(3,4-dihydroxyphenyl)acetic acid and 5-(3,4dihydroxyphenyl)- $\gamma$-valerolactone as the major metabolites, J. Agric. Food Chem., 2009, 57, 1084-1092.

$55 \mathrm{~S}$. Stoupi, G. Williamson, J. W. Drynan, D. Barron and M. N. Clifford, Procyanidin B2 catabolism by human fecal microflora: Partial characterization of 'dimeric' intermediates, Arch. Biochem. Biophys., 2010.

56 M. R. Meselhy, N. Nakamura and M. Hattori, Biotransformation of (-)-epicatechin 3-O-gallate by human intestinal bacteria, Chem. Pharm. Bull., 1997, 45, 888-893.

57 T. Kohri, M. Suzuki and F. Nanjo, Identification of metabolites of (-)-epicatechin gallate and their metabolic fate in the rat, J. Agric. Food Chem., 2003, 51, 5561-5566.

58 S. Roowi, A. Stalmach, W. Mullen, M. E. J. Lean, C. Edwards and A. Crozier, Green tea flavan-3-ols: Colonic degradation and urinary excretion of catabolites by humans, J. Agric. Food Chem., 2010, 58, $1296-1304$.

59 G. Groenewoud and H. K. L. Hundt, The microbial metabolism of (+)-catechin to two novel diarylpropan-2-ol metabolites in vitro, Xenobiotica, 1984, 14, 711-717.

60 R. Llorach, M. Urpi-Sarda, O. Jauregui, M. Monagas and C. Andres-Lacueva, An LC-MS-based metabolomics approach for exploring urinary metabolome modifications after cocoa consumption, J. Proteome Res., 2009, 8, 5060-5068.

61 S. Stoupi, G. Williamson, J. W. Drynan, D. Barron and M. N. Clifford, Procyanidin B2 catabolism by human fecal microflora: Partial characterization of 'dimeric' intermediates, Arch. Biochem. Biophys., 2010, 501, 73-78.

62 H. C. Curtius, M. Mettler and L. Ettlinger, Study of the intestinal tyrosine metabolism using stable isotopes and gas chromatography-mass spectrometry, J. Chromatogr., A, 1976, 126, 569-580.

63 R. R. Scheline, Handbook of mammalian metabolism of plant compounds, CRC Press, Boca Raton, FL, 1991, pp. 279-284.

64 G. Groenewoud and H. K. L. Hundt, The microbial metabolism of condensed (+)-catechins by rat-caecal microflora, Xenobiotica, 1986, 16, 99-107.

65 M. Urpi-Sarda, I. Garrido, M. Monagas, C. Gómez-Cordovés, A. Medina-Remón, C. Andres-Lacueva and B. Bartolomé, Profile of plasma and urine metabolites after the intake of almond [Prunus dulcis (Mill.) D.A. Webb] polyphenols in humans, J. Agric. Food Chem., 2009, 57, 10134-10142.

66 S. Touriño, E. Fuguet, M. P. Vinardelu, M. Cascante and J. L. Torres, Phenolic metabolites of grape antioxidant dietary fiber in rat urine, J. Agric. Food Chem., 2009, 57, 11418-11426.

67 L. Y. Rios, M. P. Gonthier, C. Rémésy, I. Mila, C. Lapierre, S. A. Lazarus, G. Williamson and A. Scalbert, Chocolate intake increases urinary excretion of polyphenol-derived phenolic acids in healthy human subjects, Am. J. Clin. Nutr., 2003, 77, 912-918.

68 M. Urpi-Sarda, M. Monagas, N. Khan, R. M. Lamuela-Raventos, C. Santos-Buelga, E. Sacanella, M. Castell, J. Permanyer and C. Andres-Lacueva, Epicatechin, procyanidins, and phenolic microbial metabolites after cocoa intake in humans and rats, Anal. Bioanal. Chem., 2009, 394, 1545-1556.

69 N. C. Ward, K. D. Croft, I. B. Puddey and J. M. Hodgson, Supplementation with grape seed polyphenols results in increased urinary excretion of 3-hydroxyphenylpropionic acid, an important metabolite of proanthocyanidins in humans, J. Agric. Food Chem., 2004, 52, 5545-5549.

70 B. Bartolomé, M. Monagas, I. Garrido, C. Gómez-Cordovés, P. J. Martín-Álvarez, R. Lebrón-Aguilar, M. Urpí-Sardá, R. Llorach and C. Andrés-Lacueva, Almond (Prunus dulcis (Mill.) D.A. Webb) polyphenols: From chemical characterization to targeted analysis of phenolic metabolites in humans, Arch. Biochem. Biophys., 2010, 501, 124-133.

71 A. H. Smith, E. Zoetendal and R. I. Mackie, Bacterial mechanisms to overcome inhibitory effects of dietary tannins, Microb. Ecol., 2005, 50, 197-205.

72 A. H. Smith and R. I. Mackie, Effect of condensed tannins on bacterial diversity and metabolic activity in the rat gastrointestinal tract, Appl. Environ. Microbiol., 2004, 70, 1104-1115.

73 J. D. Brooker, L. A. O’Donovan, I. Skene, K. Clarke, L. Blackall and P. Muslera, Streptococcus caprinus sp. nov., a tannin-resistant ruminal bacterium from feral goats, Lett. Appl. Microbiol., 1994, 18, 313-318.

74 K. E. Nelson, M. L. Thonney, T. K. Woolston, S. H. Zinder and A. N. Pell, Phenotypic and phylogenetic characterization of ruminal tannin-tolerant bacteria, Appl. Environ. Microbiol., 1998, 64, 3824-3830.

75 D. O. Molina, Pell AN and Hogue DE, Effects of ruminal inoculations with tannin-tolerant bacteria on fibre and nitrogen digestibility of lambs fed a high condensed tannin diet, Animal Feed Sci. Technol., 1999, 81, 69-80.

76 K. T. Chung, Z. Lu and M. W. Chou, Mechanism of inhibition of tannic acid and related compounds on the growth of intestinal bacteria, Food Chem. Toxicol., 1998, 36, 1053-1060.

77 J. Yamakoshi, S. Tokutake, M. Kikuchi, Y. Kubota, H. Konishi and T. Mitsuoka, Effect of proanthocyanidin-rich extract from grape seeds on human fecal flora and fecalodor, Microb. Ecol. Health Dis., 2001, 13, 25-31.

$78 \mathrm{H}$. Schneider and M. Blaut, Anaerobic degradation of flavonoids by Eubacterium ramulus, Arch. Microbiol., 2000, 173, 71-75.

79 L. Q. Wang, M. R. Meselhy, Y. Li, N. Nakamura, B. S. Min, G. W. Qin and M. Hattori, The heterocyclic ring fission and dehydroxylation of catechins and related compounds by Eubacterium sp. strain SDG-2, a human intestinal bacterium, Chem. Pharm. Bull., 2001, 49, 1640-1643.

80 X. Tzounis, J. Vulevic, G. G. C. Kuhnle, T. George, J. Leonczak, G. R. Gibson, C. Kwik-Uribe and J. P. E. Spencer, Flavanol monomer-induced changes to the human faecal microflora, Br. J. Nutr., 2008, 99, 782-792.

81 M. Shirai, J. H. Moon, T. Tsushida and J. Terao, Inhibitory effect of a quercetin metabolite, quercetin 3-O- $\beta$-D-glucuronide, on lipid peroxidation in liposomal membranes, J. Agric. Food Chem., 2001, 49, 5602-5608.

82 J. Terao, S. Yamaguchi, M. Shirai, M. Miyoshi, J. H. Moon, S. Oshima, T. Inakuma, T. Tsushida and Y. Kato, Protection by quercetin and quercetin 3-O- $\beta$-D-glucuronide of peroxynitrite-induced antioxidant consumption in human plasma low-density lipoprotein, Free Radical Res., 2001, 35, 925-931.

83 K. M. Janisch, G. Williamson, P. Needs and G. W. Plumb, Properties of quercetin conjugates: Modulation of LDL oxidation and binding to human serum albumin, Free Radical Res., 2004, 38, 877-884.

84 M. Natsume, N. Osakabe, A. Yasuda, S. Baba, T. Tokunaga, K. Kondo, T. Osawa and J. Terao, In vitro antioxidative activity of (-)-epicatechin glucuronide metabolites present in human and rat plasma, Free Radical Res., 2004, 38, 1341-1348.

85 C. Cren-Olivé, E. Teissier, P. Duriez and C. Rolando, Effect of catechin $O$-methylated metabolites and analogues on human LDL oxidation, Free Radical Biol. Med., 2003, 34, 850-855.

86 S. E. Pollard, G. G. C. Kuhnle, D. Vauzour, K. Vafeiadou, X. Tzounis, M. Whiteman, C. Rice-Evans and J. P. E. Spencer, The reaction of flavonoid metabolites with peroxynitrite, Biochem. Biophys. Res. Commun., 2006, 350, 960-968. 
87 Y. L. Su, J. Z. Xu, C. H. Ng, L. K. Leung, Y. Huang and Z. Y. Chen, Antioxidant activity of tea theaflavins and methylated catechins in canola oil, J. Am. Oil Chem. Soc., 2004, 81, 269-274.

88 M. Dueñas, S. González-Manzano, A. González-Paramás and C. Santos-Buelga, Antioxidant evaluation of $O$-methylated metabolites of catechin, epicatechin and quercetin, J. Pharm. Biomed. Anal., 2010, 51, 443-449.

89 H. Schroeter, J. P. E. Spencer, C. Rice-Evans and R. J. Williams, Flavonoids protect neurons from oxidized low-density-lipoproteininduced apoptosis involving c-Jun N-terminal kinase (JNK), c-Jun and caspase-3, Biochem. J., 2001, 358, 547-557.

90 S. Basu-Modak, M. J. Gordon, L. H. Dobson, J. P. E. Spencer, C. Rice-Evans and R. M. Tyrrell, Epicatechin and its methylated metabolite attenuate UVA-induced oxidative damage to human skin fibroblasts, Free Radical Biol. Med., 2003, 35, 910-921.

91 H. Nakagawa, K. Hasumi, M. Takami, S. Aida-Hyugaji, J. T. Woo, K. Nagai, T. Ishikawa and M. Wachi, Identification of two biologically crucial hydroxyl groups of (-)-epigallocatechin gallate in osteoclast culture, Biochem. Pharmacol., 2007, 73, 3443.

92 K. R. Landis-Piwowar, B. W. Sheng, R. A. Wiegand, D. J. Kuhn, H. C. Tak and Q. P. Dou, Methylation suppresses the proteasomeinhibitory function of green tea polyphenols, J. Cell. Physiol., 2007, 213, 252-260.

93 N. Ahmad, S. Gupta and H. Mukhtar, Green tea polyphenol epigallocatechin-3-gallate differentially modulates nuclear factor $\kappa \mathrm{B}$ in cancer cells versus normal cells, Arch. Biochem. Biophys., 2000, 376, 338-346.

94 D. Chen, K. G. Daniel, D. J. Kuhn, A. Kazi, M. Bhuiyan, L. Li, Z. Wang, S. B. Wan, W. H. Lam, T. H. Chan and Q. P. Dou, Green tea and tea polyphenols in cancer prevention, Front. Biosci., 2004, 9, 2618-2631.

95 H. Fujiki, M. Suganuma, S. Okabe, E. Sueoka, N. Sueoka, N. Fujimoto, Y. Goto, S. Matsuyama, K. Imai and K. Nakachi, Cancer prevention with green tea and monitoring by a new biomarker, hnRNP B1, Mutat. Res., Fundam. Mol. Mech. Mutagen., 2001, 480-481, 299-304.

96 P. Dolara, C. Luceri, C. De Filippo, A. P. Femia, L. Giovannelli, G. Caderni, C. Cecchini, S. Silvi, C. Orpianesi and A. Cresci, Red wine polyphenols influence carcinogenesis, intestinal microflora, oxidative damage and gene expression profiles of colonic mucosa in F344 rats, Mutat. Res., Fundam. Mol. Mech. Mutagen., 2005, 591, 237-246.

97 K. Iijima, M. Yoshizumi and Y. Ouchi, Effect of red wine polyphenols on vascular smooth muscle cell function - Molecular mechanism of the 'French paradox', Mech. Ageing Dev., 2002, 123, 1033-1039.

98 D. Kaul, K. Sikand and A. R. Shukla, Effect of green tea polyphenols on the genes with atherosclerotic potential, Phytother. Res., 2004, 18, 177-179.

99 T. Grimm, A. Schäfer and P. Hoögger, Antioxidant activity and inhibition of matrix metalloproteinases by metabolites of maritime pine bark extract (pycnogenol), Free Radical Biol. Med., 2004, 36, $811-822$.

100 J. D. Lambert, J. E. Rice, J. Hong, Z. Hou and C. S. Yang, Synthesis and biological activity of the tea catechin metabolites, M4 and M6 and their methoxy-derivatives, Bioorg. Med. Chem. Lett., 2005, 15, 873-876.

101 H. C. Lee, A. M. Jenner, C. S. Low and Y. K. Lee, Effect of tea phenolics and their aromatic fecal bacterial metabolites on intestinal microbiota, Res. Microbiol., 2006, 157, 876-884.

102 H. L. Alakomi, R. Puupponen-Pimiä, A. M. Aura, I. M. Helander, L. Nohynek, K. M. Oksman-Caldentey and M. Saarela, Weakening of Salmonella with selected microbial metabolites of berry-derived phenolic compounds and organic acids, J. Agric. Food Chem., 2007, 55, 3905-3912.

103 C. Cueva, M. V. Moreno-Arribas, P. J. Martín-Álvarez, G. Bills, M. F. Vicente, A. Basilio, C. L. Rivas, T. Requena, J. M. Rodríguez and B. Bartolomé, Antimicrobial activity of phenolic acids against commensal, probiotic and pathogenic bacteria, Res. Microbiol., 2010, 161, 372-382.

104 G. Glaber, E. U. Graefe, F. Struck, M. Veit and R. Gebhardt, Comparison of antioxidative capacities and inhibitory effects on cholesterol biosynthesis of quercetin and potential metabolites, Phytomedicine, 2002, 9, 33-40.

105 A. R. Rechner and C. Kroner, Anthocyanins and colonic metabolites of dietary polyphenols inhibit platelet function, Thromb. Res., 2005, 116, 327-334.

106 P. C. Karlsson, U. Huss, A. Jenner, B. Halliwell, L. Bohlin and J. J. Rafter, Human fecal water inhibits COX-2 in colonic HT-29 cells: Role of phenolic compounds, J. Nutr., 2005, 135, 2343-2349.

107 W. R. Russell, J. E. Drew, L. Scobbie and G. G. Duthie, Inhibition of cytokine-induced prostanoid biogenesis by phytochemicals in human colonic fibroblasts, Biochim. Biophys. Acta, Mol. Basis Dis., 2006, 1762, 124-130.

108 M. Monagas, N. Khan, C. Andrés-Lacueva, M. Urpí-Sardá, M. Vázquez-Agell, R. M. Lamuela-Raventós and R. Estruch, Dihydroxylated phenolic acids derived from microbial metabolism reduce lipopolysaccharide-stimulated cytokine secretion by human peripheral blood mononuclear cells, Br. J. Nutr., 2009, 102, 201-206.

109 M. Larrosa, C. Luceri, E. Vivoli, C. Pagliuca, M. Lodovici, G. Moneti and P. Dolara, Polyphenol metabolites from colonic microbiota exert anti-inflammatory activity on different inflammation models, Mol. Nutr. Food Res., 2009, 53, 1044-1054.

110 K. Gao, A. Xu, C. Krul, K. Venema, Y. Liu, Y. Niu, J. Lu, L. Bensoussan, N. P. Seeram, D. Heber and S. M. Henning, Of the major phenolic acids formed during human microbial fermentation of tea, citrus, and soy flavonoid supplements, only 3,4-dihydroxyphenylacetic acid has antiproliferative activity, J. Nutr., 2006, 136, 52-57.

111 T. Tanaka, T. Kojima, T. Kawamori, N. Yoshimi and H. Mori, Chemoprevention of diethylnitrosamine-induced hepatocarcinogenesis by a simple phenolic acid protocatechuic acid in rats, Cancer Res., 1993, 53, 2775-2779.

112 V. Krajka-Kuzniak, H. Szaefer and W. Baer-Dubowska, Modulation of cytochrome P450 and phase II enzymes by protocatechuic acid in mouse liver and kidney, Toxicology, 2005, 216, 24-31.

113 V. Krajka-Kuzniak, H. Szaefer and W. Baer-Dubowska, Hepatic and extrahepatic expression of glutathione S-transferase isozymes in mice and its modulation by naturally occurring phenolic acids, Environ. Toxicol. Pharmacol., 2008, 25, 27-32.

114 E. C. H. Yip, A. S. L. Chan, H. Pang, Y. K. Tam and Y. H. Wong, Protocatechuic acid induces cell death in HepG2 hepatocellular carcinoma cells through a c-Jun N-terminal kinase-dependent mechanism, Cell Biol. Toxicol., 2006, 22, 293-302.

115 H. H. Lin, J. H. Chen, C. C. Huang and C. J. Wang, Apoptotic effect of 3,4-dihydroxybenzoic acid on human gastric carcinoma cells involving $\mathrm{JNK} / \mathrm{p} 38$ MAPK signaling activation, Int. J. Cancer, 2007, 120, 2306-2316.

116 Y. M. Liu, B. Jiang, Y. M. Bao and L. J. An, Protocatechuic acid inhibits apoptosis by mitochondrial dysfunction in rotenoneinduced PC12 cells, Toxicol. in Vitro, 2008, 22, 430-437. 